\title{
Analyzing airport capacity by simulation
}

a Mexican case study

\author{
Author(s) \\ Zuniga Alcaraz, Catya; Mujica Mota, Miguel; Herrera García, Alfonsa \\ DOI \\ 10.4018/978-1-4666-9779-9.ch007
}

Publication date

2016

Document Version

Author accepted manuscript (AAM)

Published in

Handbook of research on military, aeronautical, and maritime logistics and operations

Link to publication

\section{Citation for published version (APA):}

Zuniga Alcaraz, C., Mujica Mota, M., \& Herrera García, A. (2016).

Analyzing airport capacity by simulation: a Mexican case study. In A.

Ochoa-Zezzatti, J. Sanchez, \& M. G. Cedillo-Campos (Eds.),

Handbook of research on military, aeronautical, and maritime logistics and operations (pp. 115-150). IGI Global Publishing.

https://doi.org/10.4018/978-1-4666-9779-9.ch007

It is not permitted to download or to forward/distribute the text or part of it without the consent of the author(s) and/or copyright holder(s), other than for strictly personal, individual use, unless the work is under an open content license (like Creative Commons).

If you believe that digital publication of certain material infringes any of your rights or (privacy) interests,

please let the Library know, stating your reasons. In case of a legitimate complaint, the Library will make the material inaccessible and/or remove it from the website. Please contact the library:

https://www.amsterdamuas.com/library/contact/questions, or send a letter to: University Library (Library of the University of Amsterdam and Amsterdam University of Applied Sciences), Secretariat, Singel 425, 1012 WP Amsterdam, The Netherlands. You will be contacted as soon as possible. 


\title{
Analyzing Airport Capacity by simulation: \\ A mexican case study
}

\author{
Catya Zuniga *, Miguel Mujica**, Alfonso Herrera*** \\ Affiliation, Country \\ *Aeronautical University in Queretaro, Mexico; **Amsterdam University of Applied Sciences, \\ Netherlands; *** Mexican Institute of Transportation, Mexico.
}

\begin{abstract}
Air transportation has grown in an unexpected way during last decades and is expected to increase even more in the next years. Traffic growth tendencies forecast an expansion in the demand and greater aviation connectivity, but also higher workload to the different airspace users, especially for airport and services. Therefore, it is essential to employ strategies designed to use efficiently valuable corporate resource. Airport authorities around the world are investing in large capital projects, including new or improved runways, terminal expansions, and entirely new airports. However, this effort is sometimes limited due to their geographic location. In this work, two main objectives are pursued: first, to highlight the importance of the industry by exposing the current situation and future trends all over the world focusing in the Mexican industry; and second, to introduce a simulation model which can be used as a decision making tool for the upcoming demand. The analysis of the scenarios illustrates how to develop strategies to cope with the different airspace user's needs.
\end{abstract}

Keywords: Discrete Event Simulation, Facility Design, Terminal Building, Airport capacity, Mexico case study, airport landside, modeling and simulation.

\section{INTRODUCTION}

The air transportation industry plays an essential role for global business and tourism but also in the economic growth worldwide. It enables countries to participate in the global economy by increasing access to international markets and, at the same time, allowing globalization of production, among many other benefits. The air transportation industry is a team effort, each time an airplane is in the air, there is needed a coordination and interaction across a complex chain of partners, from airports, airlines, air navigation service providers (ANSPs), fuel suppliers, ground handlers, systems providers, catering companies, travel agencies, security screeners, and many more.

The air transportation has grown in an unexpected way during last decades and is expected to increase even more in the next years. The industry is wide, and with an innovative and excellent increasing perspective. Investments, business operations and efficiency, around the world are encouraged by air connectivity. The industry is evolving with several organizational and technical restructuring created by the globalization itself, the constant growing economic environment, and the development of new technologies, among other factors. 
The first commercial passenger flight took place on January 1st, 1914 with a single passenger on it. Since then, the industry has not stopped growing. Twenty years later, 652000 passengers were transported on commercial flights, reaching almost 40 million in 1952. Nowadays, around 3.3 billon people are safely transported, see Figure 1. The year of 2014 was outstanding for the transportation industry; passenger traffic as measured by revenue passenger kilometers (RPK) was up nearly $6 \%$ than 2013 , and capacity was up nearly $5.8 \%$. Lower oil prices were one of the key factors for airlines profits; they accounted around 20 billion USD; but also 2014 was a record year for manufacturers such as Boeing and Airbus; over 1490 airplanes were delivered and 3680 were ordered by airlines. The air transportation business activity generated around 2.4 trillion USD.

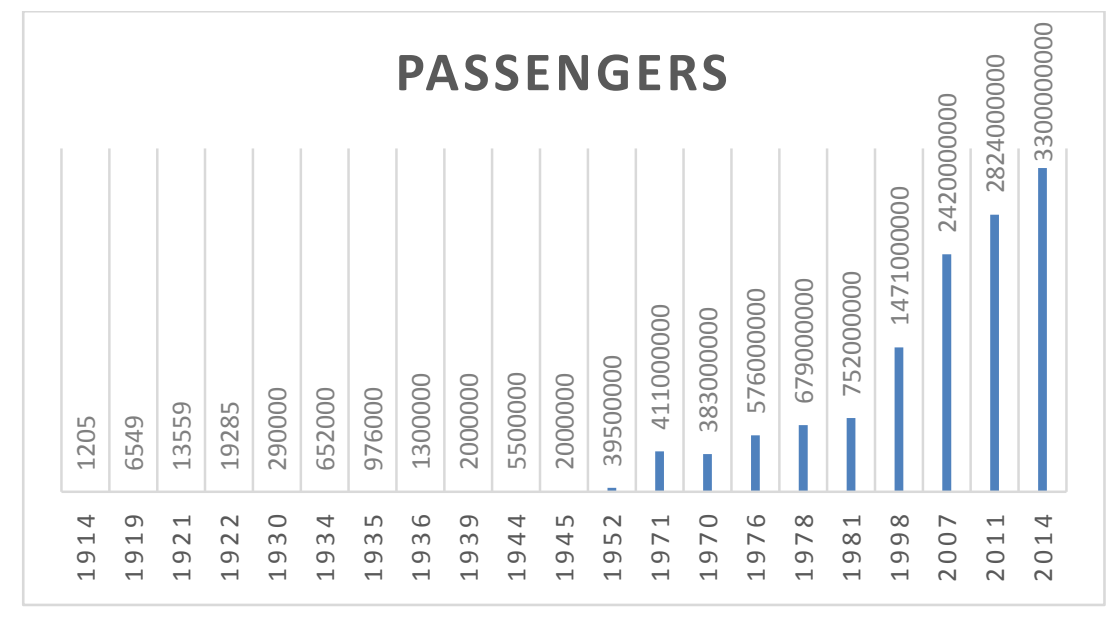

Figure 1.Evolution of Passengers carried by airlines Source (IATA,2014)

In 2014, the air transportation industry generated around of 58 million jobs in the world; around 9 million direct jobs: airlines, air navigation service providers and airports directly employed 7.6 million people. The civil aerospace manufacture sector employed more than 1 million people. It has been accounted more than 9 million indirect jobs generated through purchases of goods and services from companies in their associated supply chain. Furthermore, the tourism is enabled by air transport and it generated around 35 million jobs globally, (ATAG, 2012).

During the past decade, 2001-2011, the world economy grew at an average annual rate of 3.6\%, measured in terms of Gross Domestic Product (GDP). In the same period, the total scheduled airline traffic grew at an average annual rate of 5\%, reaching around \$2.6 billion USD annually in RPK, totaling nearly 5 trillion USD in 2010, and nearly 48 million tons of freight reaching to 172 billion freight ton kilometers (FTK). The total value of goods transported by air in 2011 represented the $35 \%$ of all international trade, (ATAG, 2012).

The air transport industry is a complex system, along with its different airspace users, airports, ANSPs, airlines, manufacturers, regulators, and multiple international organizations worldwide. Traffic growth tendencies forecast an expansion in the demand and greater aviation connectivity, even with multiple crises over the years. Unfortunately, higher demand means higher workload to the different airspace users, especially for airport and ANSPs. They are facing new challenges which require that government and industry work together, but with excellent opportunities to share, develop or enhance their capacity (Belobaba, 2009), (Odoni, 2013).

Therefore, it is essential to employ airport management strategies designed to use efficiently valuable corporate resource within airport in order to meet the demands of the diverse airspace users. Airport 
authorities around the world are investing in large capital projects, including new or improved runways, terminal expansions, and entirely new airports. However, some airports are limited for expansions because of their geographic location, meaning that it is very complicated to face the increasing passengers' traffic demand by projects that involve infrastructure growth. On the other hand, airlines have implemented diverse approaches to manage traffic growth. They have been replacing smaller airplane by bigger ones to increase the cost/efficiency ratio. Code sharing, the development of alliances and joint ventures are all also different ways to cope with the increasing demand (Belobaba, 2009), (Odoni, 2013). Secondary hubs, expanding service (route decentralization) to secondary airports have also been proposed to ease congestion at the busiest airports. Air Traffic Management promotes collaboration among all subsystems in order to improve decision making.

Diverse modernization projects such as The Single European Sky ATM Research (SESAR) launched by the European Community and the Next Generation Air Transportation System (NextGen) launched by US government, among others, are aimed to ensure the safety and fluidity of Air Transport over the next thirty years. These projects are revisiting some key aspects to overhaul airspace systems (EUROCONTROL, 2011).

In consequence, it is necessary to exploit different techniques for analyzing the use of the different system resources. Simulation answers the questions; What if?, through the display and analysis of different scenarios in which many variables (deterministic and stochastic) can be investigated. A simulation approach can provide the means to incorporate different stakeholder issues and provide effective 'what-if' analysis based on different scenarios. The simulation technique allows analyzing diverse activities and processes for managing in a sustainable manner airport and air traffic infrastructure. Specially, Discrete Event Simulation (DES) involves events (arrival, departure, etc.) that occur at discrete points in time. Hence, DES models are dynamic, stochastic and discrete by nature, i.e., the passage of time plays a crucial role while some uncertainties can be modeled in certain and known time periods (Banks et al, 2010).

Over the last years, there have been several studies which exploited the benefits of a DES approach. These studies have modeled a wide range of systems, from human systems to underground haulage systems, and more. Moreover, the models have proved value to this technique. In the air transport industry, it has been also widely used to support airport stakeholder decision-making process (Neufville, 2013).

In this work, two main objectives are pursued: first, to highlight the importance of the industry by exposing the current situation and future trends all over the world focusing in the Mexican industry; and second, to introduce a simulation model which can be used as a decision making tool for the upcoming demand. The departure process in a medium size airport terminal building in Mexico is analyzed using two different scenarios. The analysis of the scenarios illustrates how to develop strategies to cope with the different airspace user's needs.

This work is organized as follows. Section 1 introduces the importance of the industry by means of its current and future growth tendencies around the world and particularly in Mexico. In section 2 is examined the typical design process of a passenger terminal building and then, later on, in section 3 , it is referred to some of the works published on analysis and design of the process within terminal buildings to enhance capacity. Section 4 is focused on modeling the departure process using a Discrete Event Simulation approach. Finally, Section 5 shows some preliminary results to highlight the benefits of the simulation approach. At the end of the work, conclusion and further work are presented. 


\section{THE AIR TRANSPORTATION INDUSTRY IN NUMBERS}

The economic impact of the air transportation industry, particularly the commercial sector, is crucial around the world. As previously said, in 2014, 3.3 billion people were transported safely all over the world, not forgetting the cargo sector with 50 million metric tons moved during the same year, (IATA, 2014). The aviation's global economic benefits are quite big; it is estimated at $\$ 2.2$ trillion USD in direct, indirect, induced and tourism-catalytic included (ATAG, 2012). For instance, in the United States, one of the leaders of the sector, the commercial aviation represents around 8\% of their GDP. The annual investment in American airport infrastructure was nearly \$10 billion USD; in 2010 airports invested \$26 billion USD in construction projects. The number of passengers has risen and cargo volumes have grown fourteen fold, despite repeated shocks from recessions, wars, terrorism and disease (ICAO, 2013), (IATA, 2013).

In 2013, over 1500 airlines operate a total fleet of nearly 20310 airplanes serving almost 4000 airports and managed by around 190 air navigation service providers, (ATAG, 2012). Airlines all around the globe have put on new services for the network connectivity, with a seasonal peak to over 40000 pairs, an increase of $2.5 \%$ over the same month a year earlier (IATA, 2011). In 2014 a total of 50000 scheduled airport pairs registered a $\$ 6.6$ trillion USD as result to the connectivity (IATA, 2014). In 2012, the airlines registered an impressive $11 \%$ growth, while during 2011 the growth was about $7.5 \%$. It has been forecasting for the year 2031 around 30.17 million passengers with an average annual growth of $8.9 \%$ and 400 million tons of cargo (ICAO, 2013). In 2012, CAR-SAM region registered 119 commercial airlines from which it can be pointed out in two largest markets: Brazil and Mexico, representing the $17 \%$ and $19 \%$, respectively.

Regarding the air traffic passengers' distribution in the world in 2010, the Asian-Pacific region had over the $36 \%$ of passengers while North American region and Europe, obtained the 27\% of the total. Latin America and the Central America and South America Region (CAR-SAM) transported the 6\% of the world passengers.

For instance, Europe accounted between 25000 and 30000 flights daily, using 5000 airplanes which land and depart from around 1000 airports. The economic benefits generated by the European air transport industry are approximately of 20000 million USD per year. The contribution of the European Air Traffic Management is over 9000 million dollars per year, representing approximately the $45 \%$ of the total obtained benefits. On the other hand, in the United Sates, the airline company market was conformed by over 2000 airline companies with approximately 23000 commercial airplanes, that provided services to over 3700 airports (IATA, 2013).

In 2013, the biggest fleet was owned by United States, with a total of 6590 airplanes, followed by Asia Pacific region with 5090 and Europe with 4390. Latin America and Middle East account for 1280 and 1140 respectively. New airplanes replaced older, less efficient airplanes, reducing the cost of air travel and decreasing carbon emissions. Nowadays, United States still owns the biggest fleet, with 6700 airplanes, but not for much, the Asia Pacific region keeps growing with a total of 5850 airplanes, i.e. new 760 airplanes were received in around 2 years with a value of 2200 billion USD. Most of Asia Pacific fleet is composed by single aisle airplanes, around $70 \%$, other $13 \%$ is represented by small widebody airplanes and almost $10 \%$ is medium widebody.

The Asia Pacific region has demanded 12820 new airplanes with a total value of 1890 billion USD. In the case of Europe and United States, 7460 and 7250 airplanes with a value of 1020 billion USD and 810 USD, respectively, have been demanded. Latin America has also asked for 2900 airplanes with a value of 300 billion USD. It has been predicted that in 2032 the Asia Pacific region will account with the biggest fleet, 14750 airplanes in total, followed by United States with 8810 and Europe with over 7000. Latin 
America will improve its fleet with a total of 3790 in the same year. But not only more airplanes have been requested also the seat occupancy have become more productive, i.e. the load factors has incremented to an $80 \%$, see Figure 2.

In 2013, there were nearly 7780 airports in the world with IATA/ICAO identification code, $34 \%$ of them belong to United States of America, followed by the $25.64 \%$ of Europe, and the $12.57 \%$ corresponded to Latin America. In the same year, the world registered over 82 million aircraft movements, from which North America region made the $35.8 \%$ of the total, followed by Europe with the $25.3 \%$ and Asia Pacific with the $22 \%$. Latin America and CAR/SAM accounted a 10\% of the total of movements and Africa and Middle East represented each one around the 3\% of the total (ACI, 2012). In 2013, Atlanta was the busiest airport on the globe both in movements and passenger transported, with 911074 movements and 94.4 million passengers. Chicago airport takes the second place with 883287 movements and Los Angeles airport is in the third place, 696443 movements.
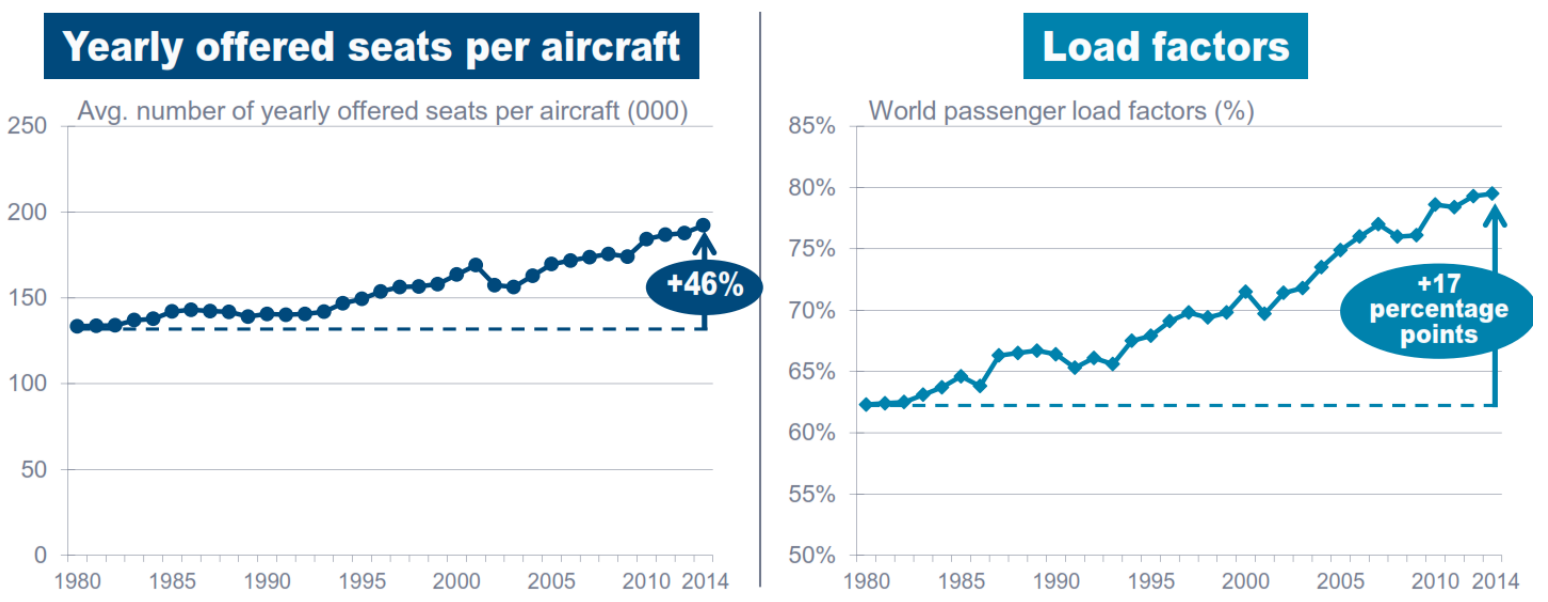

Figure 2. Passengers carried by airlines in 2010 Source (ATAG, 2012)

According to AIRBUS (2014), 47 mega-cities, airports, possess the mayor air traffic in the world moving around 0.9 million passenger per day. Table 1 provides detailed information about top 10 busiest airports in the world. It has been forecasted that in 2034 there will be 91 mega-cities moving daily around 2.3 million passengers. Furthermore, 39 out of 47 airports are already constrained, see Figure 3.

Regarding cargo operations, Table 2 introduces the top 10 cargo airports in 2013, where Hong Kong (HKG) and Memphis (MEM) took the first places as the busiest airports in terms of air cargo traffic. Each airport handled over 4 million metric tons in 2013. Meanwhile, as a region, Asia-Pacific region handled the largest amount of air cargo during the same year, moving 37 million metric tons, followed by North America with 27.9 million metric tons. Europe also represents a good player within the industry, moving 17.8 million metric tons. Middle East and Latin America-Caribbean moved 6.5 million and 5.1 million metric tons, respectively (ACI, 2013).

Today, there are nearly 1,650 dedicated freighter aircraft with a cargo hold of at least 10 tons and more than 200 airlines. For the period 2013-2032, worldwide air freight is expected to grow at $4.8 \%$ per year; a demand for 1,859 converted aircraft and 871 new aircraft is also predicted. 


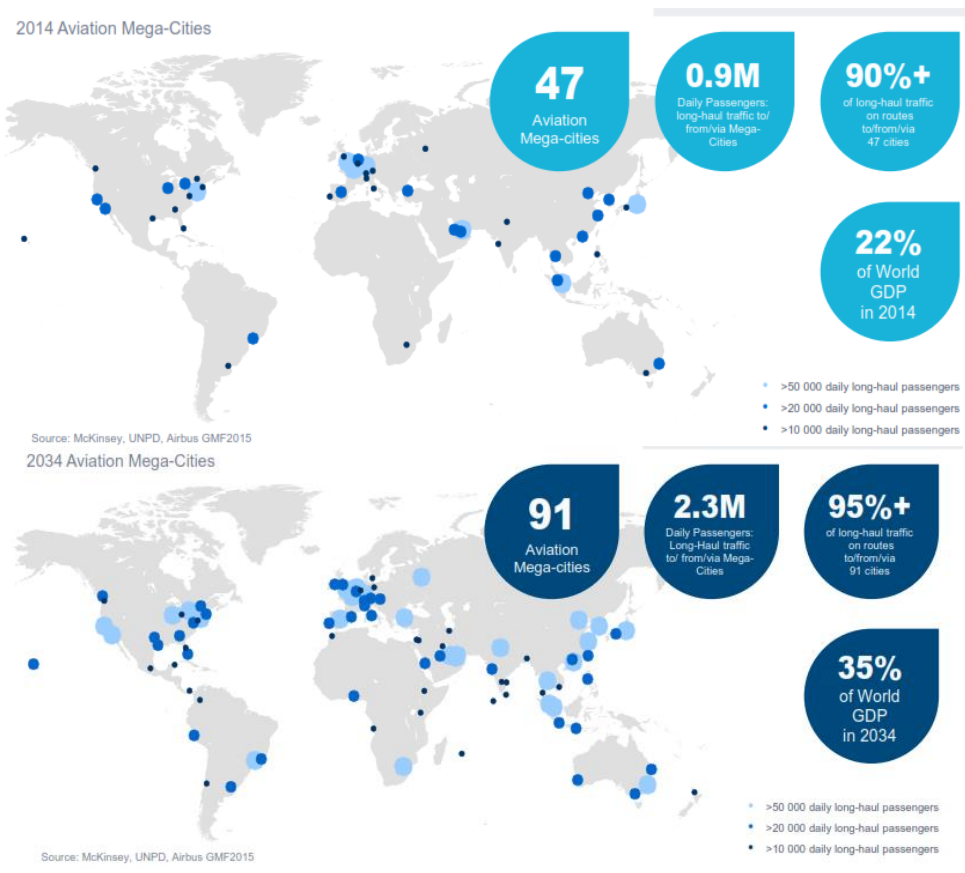

Figure 3. Current and future mega-cities in the world Source (AIRBUS, 2014).

Table 1. Top 10 busiest airports by passengers in the world Source: (ACI, 2013)

\begin{tabular}{|c|c|c|c|c|c|}
\hline $\begin{array}{l}\text { RANK } \\
2013\end{array}$ & $\begin{array}{l}\text { RANK } \\
2012\end{array}$ & CITY & CODE & $\begin{array}{c}\text { TOTAL } \\
\text { PASSENGERS }\end{array}$ & $\begin{array}{c}2013 / 2012 \% \\
\text { CHANGE }\end{array}$ \\
\hline 1 & 1 & Atlanta GA, USA & ATL & 94431224 & $-1.1 \%$ \\
\hline 2 & 2 & Beijing, China (People's Rep. of China) & PEK & 83712355 & $2.2 \%$ \\
\hline 3 & 3 & London, United Kingdom & LHR & 72368061 & $3.3 \%$ \\
\hline 4 & 4 & Tokyo, Japan & HND & 68906509 & $3.2 \%$ \\
\hline 5 & 5 & Chicago IL, USA & ORD & 66777161 & $0.2 \%$ \\
\hline 6 & 6 & Los Angeles CA, USA & LAX & 66667619 & $4.7 \%$ \\
\hline 7 & 10 & Dubai, United Arab Emirates & DXB & 66431533 & $15.2 \%$ \\
\hline 8 & 7 & Paris, France & CDG & 62052917 & $0.7 \%$ \\
\hline 9 & 8 & Dallas/Fort Worth TX, USA & DFW & 60470507 & $3.2 \%$ \\
\hline 10 & 9 & Jakarta, Indonesia & CGK & 60137347 & $4.1 \%$ \\
\hline
\end{tabular}

Table 2. Top 10 busiest airports by cargo in the world Source: (ACI, 2013)

\begin{tabular}{|c|c|c|c|c|c|}
\hline \multicolumn{6}{|c|}{$\begin{array}{l}\text { TOP } 10 \text { AIRPORTS BY AIR CARGO } 2013 \\
\text { Freight and mail in metric tonnes }\end{array}$} \\
\hline $\begin{array}{l}\text { RANK } \\
2013\end{array}$ & $\begin{array}{l}\text { RANK } \\
2012\end{array}$ & CITY & CODE & TOTAL CARGO & $\begin{array}{l}2013 / 2012 \% \\
\text { CHANGE }\end{array}$ \\
\hline 1 & 1 & Hong Kong, China & HKG & 4166303 & $2.4 \%$ \\
\hline 2 & 2 & Memphis TN, USA & MEM & 4137801 & $3.0 \%$ \\
\hline 3 & 3 & Shanghai, China (People's Rep. of China) & PVG & 2928527 & $-0.3 \%$ \\
\hline 4 & 5 & Incheon, Korea (Rep. of Korea) & ICN & 2464384 & $0.3 \%$ \\
\hline 5 & 6 & Dubai, United Arab Emirates & DXB & 2435567 & $6.8 \%$ \\
\hline 6 & 4 & Anchorage AK, USA & ANC $^{*}$ & 2421145 & $-1.7 \%$ \\
\hline 7 & 7 & Louisville KY, USA & SDF & 2216079 & $2.2 \%$ \\
\hline 8 & 9 & Frankfurt, Germany & FRA & 2094453 & $1.4 \%$ \\
\hline 9 & 8 & Paris, France & CDG & 2069200 & $-3.8 \%$ \\
\hline 10 & 10 & Tokyo, Japan & NRT & 2019844 & $0.7 \%$ \\
\hline
\end{tabular}


The airports in Latin America with mayor passengers' traffic are the International Airport of São PauloGuarulhos (São Paulo, Brazil), the Mexico City International Airport (MCIA) (Mexico City, Mexico) and the International Airport El Dorado (Bogotá, Colombia) (ICAO, 2013). México and Brazil are the principal representatives of the low cost carrier sector in Latin America, see Figure 4.

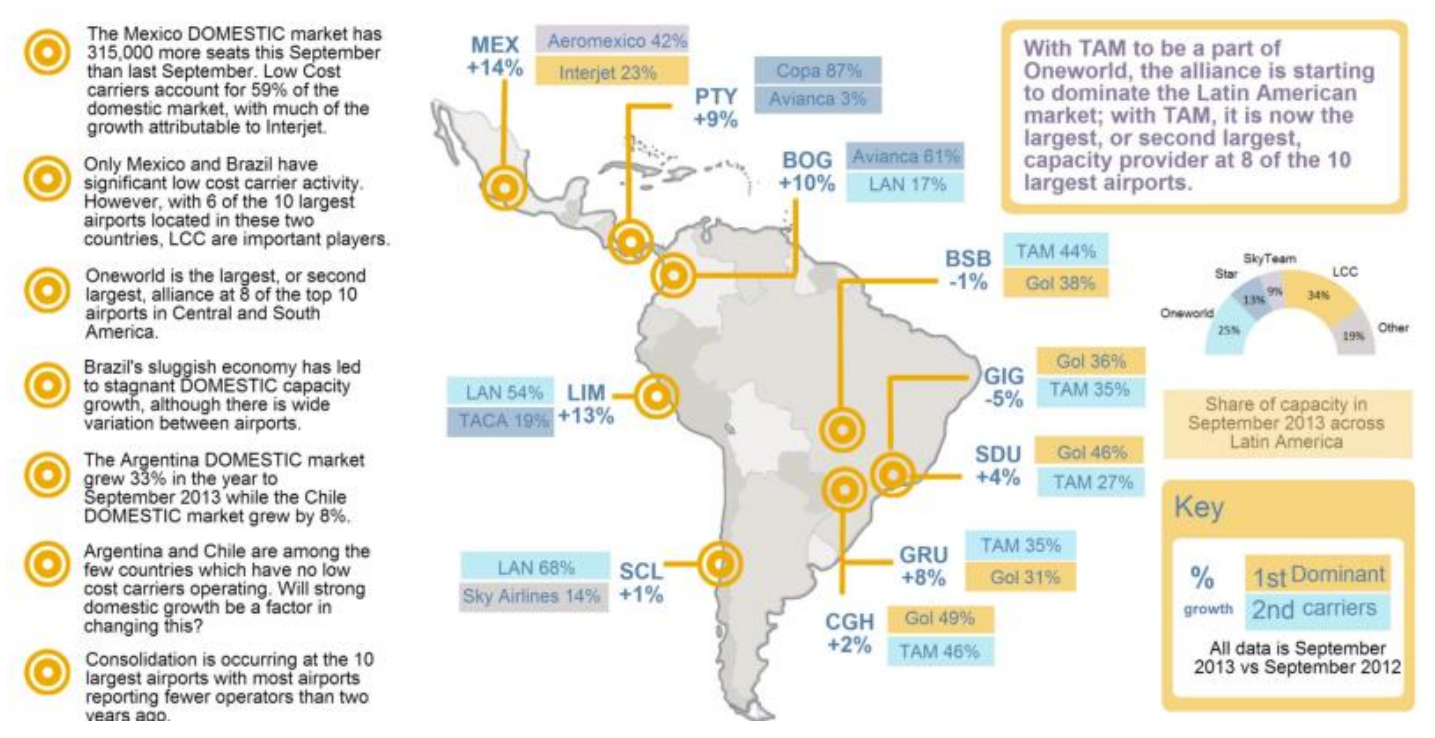

Figure 4. Latin America's top 10 airports Source: (ICAO, 2013)

Mexico transported in 2012 over 56.8 million passengers through 618 regular routes, 355 international and 263 domestic. The Mexican Airline industry operated more than 9369 airplanes, 2166 commercial service, 6632 private and 569 from government service during that year. Passenger traffic grew around $8 \%$ (RPK), it moved 605.4 mil tons of cargo in the same year, which meant a 7\% reduction in comparison with 2011 (651 200 tons). The total number of operations have reached more than 1 million, 748000 of the total correspond to domestic flights and 281000 to international ones. On the other hand the domestic sector has been growing faster than the international one, it increased in $10 \%$ over the previous year transporting 34 million passengers (60\% of the total) while the international only increased a $7 \%$ moving 22 million passengers (SCT, 2015), (ICAO, 2013), (IATA, 2013).

\section{The Mexican transport system}

Mexico transported in 2014 over 65 million passengers, an increase of 8.5\% compare with previous year. The total number of operations have reached more than 1 million, 800 mil of the total correspond to domestic flights and over 290000 to international ones. The domestic airline sector has been growing faster than the international one, it were transported 40.6 million passengers (62.5\% of the total) while the international only increased a 7\% moving 24.4 million passengers. Figure 5 shows 7 out of the 9 regular passenger commercial airlines in México which serve domestic and international routes in 2014. It can be noticed that the biggest domestic airlines in terms of transported passengers are Aeromexico, Volaris, Interjet and Aeromexico Connect which moved 9510, 9363, 8694 and 7488 million passengers, respectively. The rest of passengers, i.e. 298 000, where transported by 8 charter airlines (SCT, 2015).

Viva Aerobus, which started in 2006 its services is growing quite fast and is forecasted to be one of the leaders in the low cost sector. In fact, as it can be seen in Figure 6, the low cost sector is gaining force since 2005, and in 2013 it accounted with the $60 \%$ of the market. Volaris and Interjet together with Viva Aerobus are categorized as the current Mexican low cost carriers. 


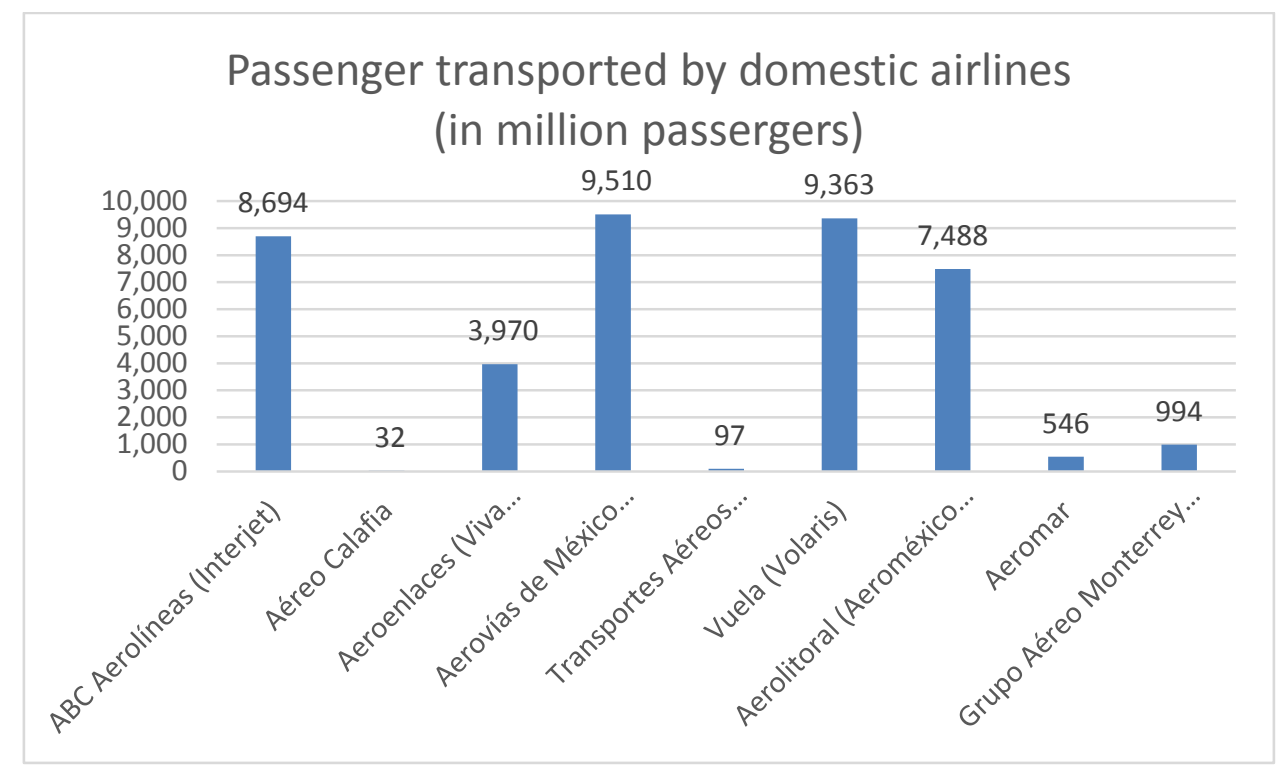

Figure 5. Passenger transported by domestic airlines in domestic and international routes in 2014 Source: $(S C T, 2015)$

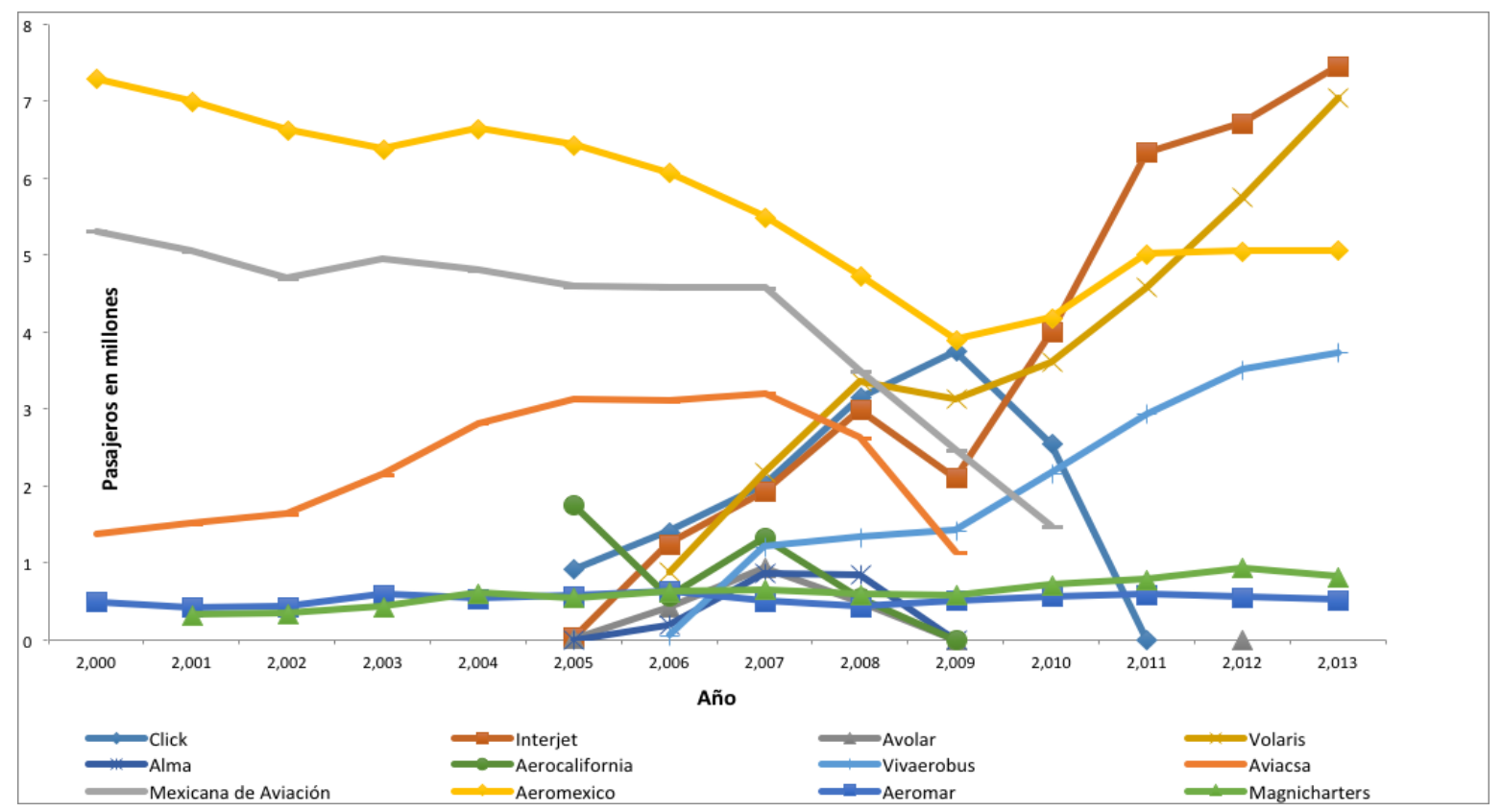

Figure 6. Main development of Mexican airlines since 2005 Source: SCT (2013)

It has been accounted 750 regular routes, 402 international and 348 domestic routes. Table 3. and Table 4 introduce the top 10 domestic routes. Within the domestic routes, 47 concentrate the $80.2 \%$ of the total passengers; while the $80 \%$ of the international tourism uses 94 routes (SCT, 2015). 
Table 3. Top 10 domestic routes in México Source: SCT (2015)

\begin{tabular}{|c|c|c|c|c|c|c|c|}
\hline & Origin & Destination & $\begin{array}{c}\text { Tran } \\
\text { pass }\end{array}$ & $\begin{array}{l}\text { oorted } \\
\text { ngers }\end{array}$ & Growing & $\begin{array}{r}\text { Or } \\
\text { Destin }\end{array}$ & $\begin{array}{l}\text { gin- } \\
\text { tion vs. }\end{array}$ \\
\hline & & & (thou & ands) & & To & \\
\hline & & & 2013 & 2014 & $2013 / 2014$ & 2013 & 2014 \\
\hline 1 & Mexico & Cancun & 3,295 & 3,524 & $7.0 \%$ & $10.8 \%$ & $10.7 \%$ \\
\hline 2 & Monterrey & Mexico & 2,460 & 2,736 & $11.2 \%$ & $8.1 \%$ & $8.3 \%$ \\
\hline 3 & Mexico & Guadalajara & 2,278 & 2,379 & $4.4 \%$ & $7.5 \%$ & $7.2 \%$ \\
\hline 4 & Tijuana & Mexico & 1,241 & 1,266 & $2.0 \%$ & $4.1 \%$ & $3.8 \%$ \\
\hline 5 & Mexico & Merida & 1,050 & 1,131 & $7.8 \%$ & $3.4 \%$ & $3.4 \%$ \\
\hline 6 & Tijuana & Guadalajara & 941 & 1,025 & $9.0 \%$ & $3.1 \%$ & $3.1 \%$ \\
\hline 7 & Villahermosa & Mexico & 700 & 776 & $11.0 \%$ & $2.3 \%$ & $2.4 \%$ \\
\hline 8 & Tuxtla Gutierrez & Mexico & 684 & 728 & $6.5 \%$ & $2.2 \%$ & $2.2 \%$ \\
\hline 9 & Monterrey & Cancun & 673 & 712 & $5.9 \%$ & $2.2 \%$ & $2.2 \%$ \\
\hline 10 & Puerto Vallarta & Mexico & 527 & 606 & $14.9 \%$ & $1.7 \%$ & $1.8 \%$ \\
\hline
\end{tabular}

Table 4. Top 10 international routes in México Source:SCT (2015)

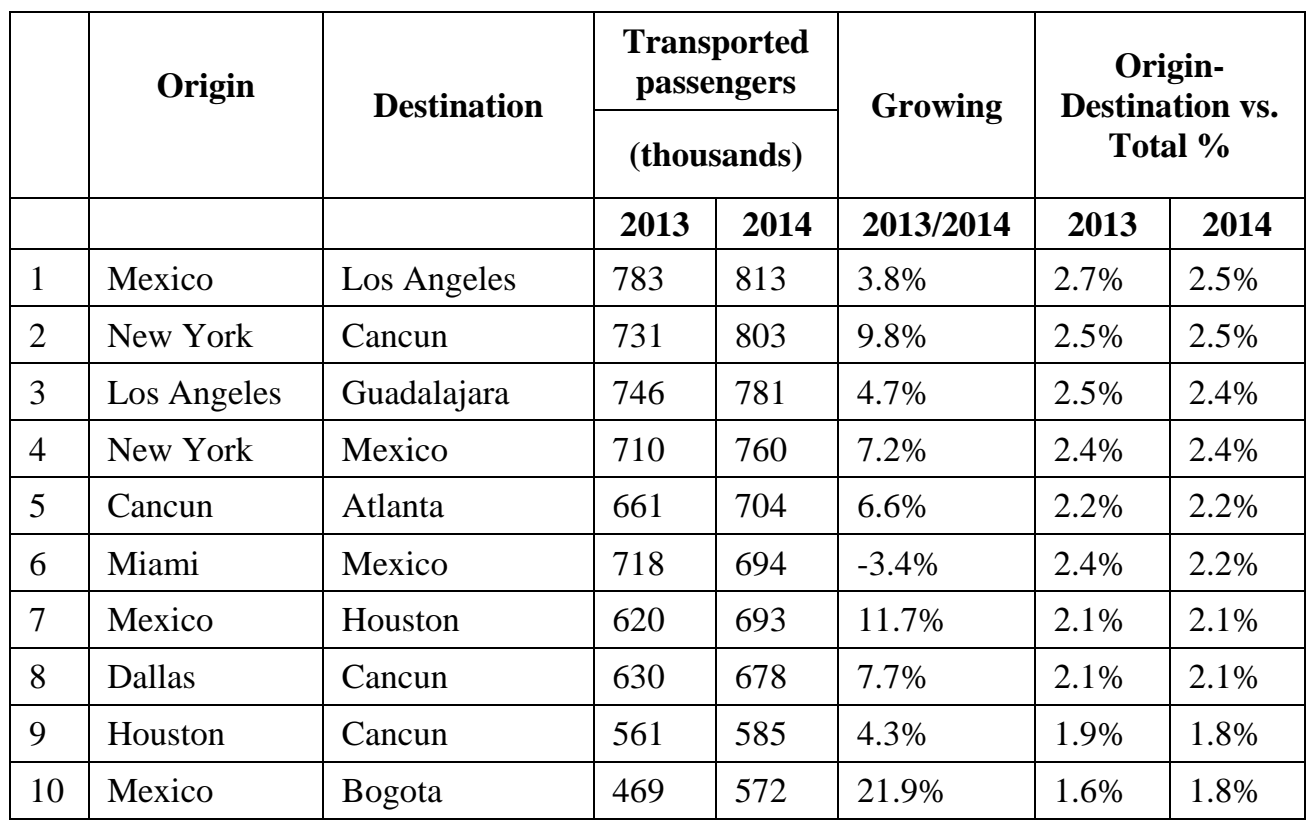

Figure 7 shows the international traffic by region carried by Mexican airlines in 2014. It can be noticed that most of the passengers come from United States, this could be linked to two main factors, the first one is the alliances between airlines and the currently used hub and spoke model of airports; and the big amount of Mexican living in this country. Aeromexico transported the biggest amount of passengers to United States with a total of 2.8 million in 2014, followed by Volaris with almost 1.7 million. To Europe, Asia and Canada, Aeromexico was the only airline which transported passengers, a total of 384, 120 and 
83 thousand passengers were accounted, respectively. To Central America and the Caribbean, Aeromexico, Aeromexico Connect and Interjet transported 196 000, 235000 and 270000 passengers, respectively. To South America, there were transported by Aeromexico and Interjet 881 and 76 thousand passengers, respectively (SCT, 2015).

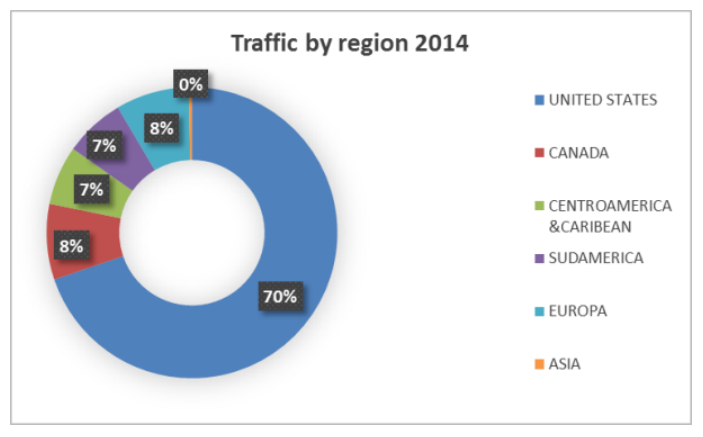

Figure 7. International traffic by region Source: (SCT, 2015)

617.5 million tons of cargo were moved in 2014, which meant a 5.6\% increase in comparison with 2013. From the total cargo moved, $43.1 \%$ corresponded to domestic carriers and $56.9 \%$ to international ones. The Mexican carriers moved almost 285000 tons. Within the commercial carriers, the most prominent were Aeromexico which moved 57.5 tons, followed by Volaris, Aeromexico Connect and Interjet moving 16.4, 15.1 and 10.9 tons, respectively. The specialized cargo carriers moved 183000 tons, Mas Air, Aero Unión and Estafeta were the top 3 carriers moving 71 100, 62800 and 30800 tons, respectively. International cargo was guided by United States and Europe whose airlines moved 160000 and 123000 tons, followed by Central and south American carriers with almost 41000 tons. The Asiatic carriers movement accounted for 26500 tons. Figure 8 introduces the flight concentration regarding the cargo in the airport system. It can be noticed that Mexico City International Airport moves the $65.4 \%$ of the total international cargo in Mexico and 38\% in the domestic sector. Guadalajara is a prominent competitor with $19.2 \%$ of the international cargo and $15 \%$ of the domestic cargo.
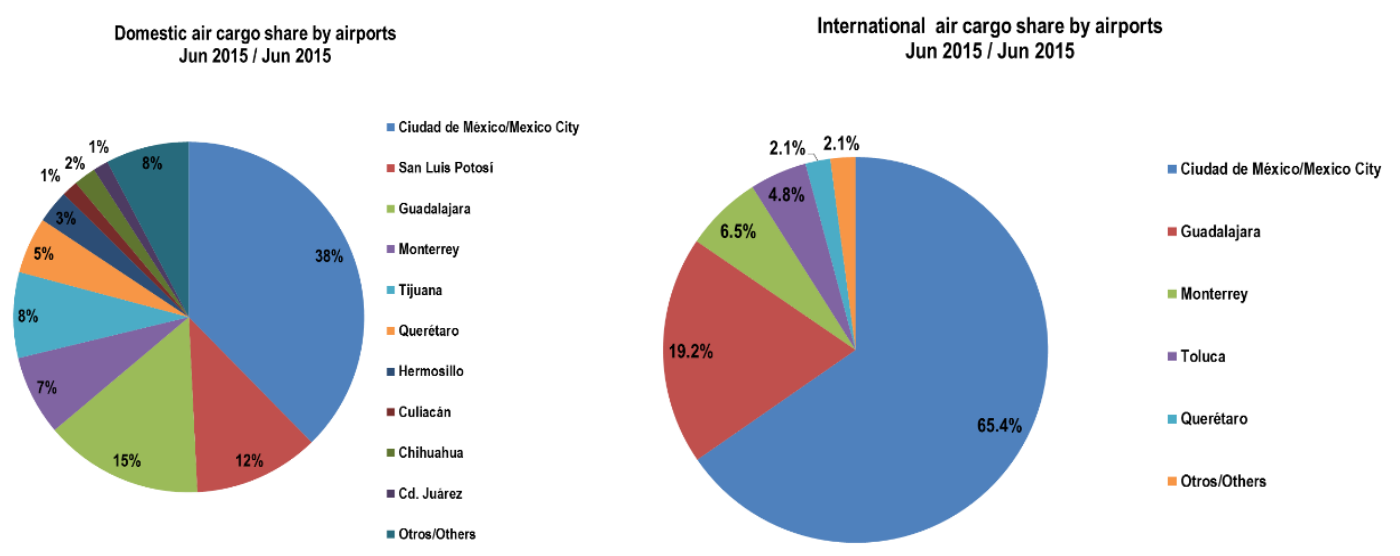

Figure 8. Domestic and International cargo by main airports in Mexico Source: SCT (2014)

The Mexican Airline industry operated 8961 aircraft, from which 2011 were for commercial services, 6509 were private and 441 were for government service. The 2011 aircraft registered in the commercial services included commercial and cargo airlines and aerotaxis. Commercial airlines owned 289 aircraft with the following distribution: Aeromexico and Aeromexico Connect accounted 64 aircraft each one, followed by Interjet and Volaris with 52 and 44 aircraft, respectively. Viva Aerobus owned 21 aircraft, 
Aeromar 19 and Magnicharters11. There were 54 aircraft owned by cargo airlines, Aeronaves TSM had the biggest amount of aircraft 31 in total, Aeroservicios de la Costa, Aero Union, Estafeta Carga Aerea and Aerotransportes MAS de Carga (MAS AIR) had 7, 6, 6 and 4 aircraft respectively.

Mexico counts with 76 airports, 63 of them are international airports and 13 domestic, in addition there are 1431 aerodromes register in the country. This places Mexico as one of the first countries in Latin America with the major airport network. The states of Coahuila, Sonora and Tamaulipas, in the north part of the country, register 5 international airports each one, followed by Baja California and Baja California South with 4 international airports each, placing them as the states with the biggest concentration of international airports in the country. Quintana Roo, Oaxaca and Sinaloa have each one 3 international airports.

Figure 9 introduces the 10 top airports by passenger traffic within Mexico in 2015. It can be noticed that Mexico City International Airport moves the 35\% the total domestic traffic of the country, followed by far for four other airports: Monterrey (10\%), Guadalajara (9\%), Cancun (8\%) and Tijuana (6\%), respectively. In the international context, Cancun International airport is a good opponent to Mexico City International airport moving $34 \%$ and $33 \%$ of the total, respectively.
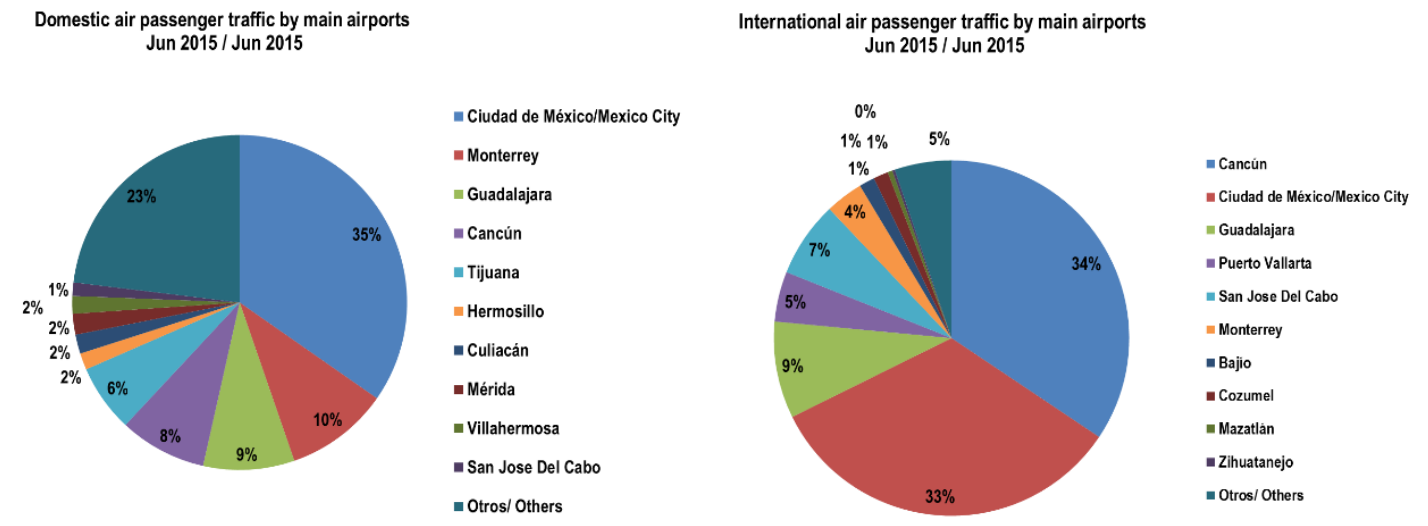

Figure 9. Domestic and International passenger traffic by main airports in Mexico Source: SCT (2014)

It can be said that the busiest airport in Mexico is called Mexico City International Airport (ICAO code: MMMX), located in Mexico city, and which also conforms, since 2003 the pillar of the Metropolitan Airport system, together with Queretaro, Puebla, Toluca and Cuernavaca. In 2014, it moved almost 34.2 million passenger, from which more than 22.7 million were domestic and around 11 million international. The amount of domestic and international passengers transported, located MMX as the first and second top 10 airports in Mexico. In the cargo sector, MMMX moved almost 33500 tons from which 27600 tons where from international destinations and 5700 domestic ones. This located MMMX as the main airport for international and domestic cargo controlling the $65 \%$ and $38 \%$ of the total, respectively, see Figure 8. The airport handled over 410000 flight operations, most of them were commercial flights: $65 \%$ were domestic and $23 \%$ international; the cargo carriers performed 11252 operations which represented the $3 \%$ of the movements. However, the domestic general aviation sector accounted with the $8.5 \%$ of the total movements.

The first international airport is Cancun, located in the state of Quintana Roo in Southeastern Mexico. Quintana Roo is also the home of the islands of Cozumel and Isla Mujeres, which together with Cancun are one of the first tourist destinations in Mexico and in the world. Cancun international airport (ICAO code MMUN) is one of the busiest airports in the Caribbean and in Mexico. In 2014 it transported almost 
17.5 million passengers from which 12 million were international and 5.4 million were domestic travelers.

\section{ANALYZING PROCESSES WITHIN PASSENGER TERMINAL BUILDINGS}

Nowadays, an efficient design and operation of terminals buildings is essential, especially in view of the increasing demand all over the world. Terminal buildings are intermodal facilities that help to transfer passengers and goods between air and land transportation. Given the projected traffic increase, it is critical that new or existing terminals move efficiently large volumes of air passengers while providing a pleasant atmosphere for traveling and a harmonious operation within it. Terminals should be designed to naturally direct air passengers from the terminal curb to the gate, passing through each of the processes smoothly.

Those processes include ticket counters, check-in counters, security controls, passport controls, baggage carousels, customs counters, holding areas (e.g. lobbies, atria, gate lounges, etc.) and passageways (e.g. corridors, escalators, moving sidewalks, etc. plus amenities, such as restrooms, restaurants, shop, banks and other facilities required. In addition to move efficiently passengers, terminal buildings also should provide passengers, employees and other airport user's services to make their stay at the airports pleasant.

Analyzing the different process that occur within the passenger terminal buildings could be somehow quite similar than the design process. Normally, a process analysis can be used to improve the understanding of how the process operates, and to determine potential targets for process improvement through removing waste and increasing efficiency. It is needed a 'as-is' process mapping and measurement of the different activities within it but also as in a design process, it is needed start from a green field and map out the process together with the employees as it 'should-be'. The process analysis 'as-is' is the assessment of the current situation in diverse aspects: a) it answers the questions What is the problem?; How are things done?; and Where are the root causes of the problems?. The process analysis consists on the following steps: define objective and scopes, locate and gather data, map actors, functions and relationships of the process, verified, validate and analyze the current behavior of the system. Following this, an identification of possible improvements can be performed, see Figure 10.

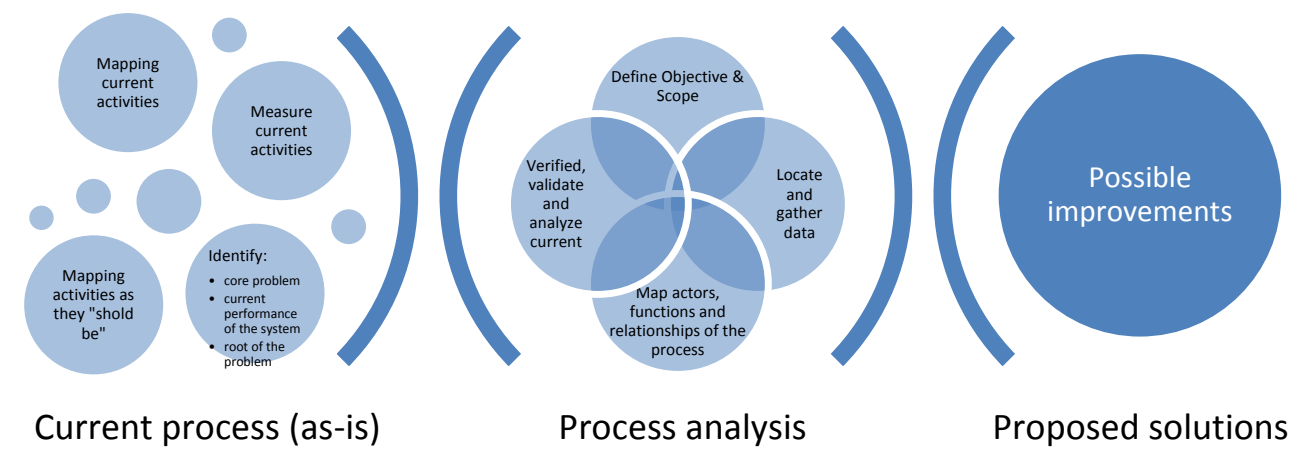

Figure 10. Process Analysis

To understand the processes, facilities and services provided for passengers travelling through airports, and how to monitor and maintain efficient passenger flow are needed. Particularly, for the design and analysis of terminal, it is needed forecasting, specification of level-of-service, flow analysis and design/analysis of spaces (De Neufville, R., \& Odoni, A., 2003), (Odoni, 1992). 
Forecasting traffic levels for peak hours: A traffic forecast is the basis not only for capacity and resource planning at an airport, but also provides the foundation for an airport's business development and overall strategy. The objective of this exercise is to produce highly detailed, peak-hour demand scenarios for the design day many years ahead. Therefore, the definition of the passenger peak-hour is fundamental for a facility's design purposes. There are many definitions for the "peak-hour" concept at an airport, but most of them encompass a key concept: planning should aim to satisfy demand at some level below this peak, i.e. the majority of passengers receive adequate service levels and only an acceptably small proportion experience the impact of congestion, with just a few hours of operation during the year in which this passenger throughput might be surpassed (Wang, 1999).

The forecast, in turn, is used to develop hour-by-hour traffic scenarios, down to the level of a specific schedule of flights, for which assumptions must be made concerning the type of aircraft involved, their origin or destination, load factors, percentage of transfer or transit passengers, etc. However, according to Odoni et al (1992), forecasts are demonstrably inaccurate but extremely helpful and necessary to develop strategic and operational plans. Even though, frequent revisits to key operations are needed to ensure the level-of-service standards and the proper airport performance. Forecasts must be done for both airside and landside to have estimation on future activity in each area. The level and type of aviation activity expected at the airport are some of the key factors that determine the parameters that must be forecasted. Generally, the most important activity forecast for airfield planning is the level and type of aviation demand generated at the airport (as measured by aircraft operations), because this demand that defines the runway and taxiway requirements. Some of the key airfield typical design parameters are depicted in Figure 11. For the landside, the most important activity to be forecasted corresponds to ground handling services, traffic flows and type and destination of passengers (FAA DOC), see Figure 12.
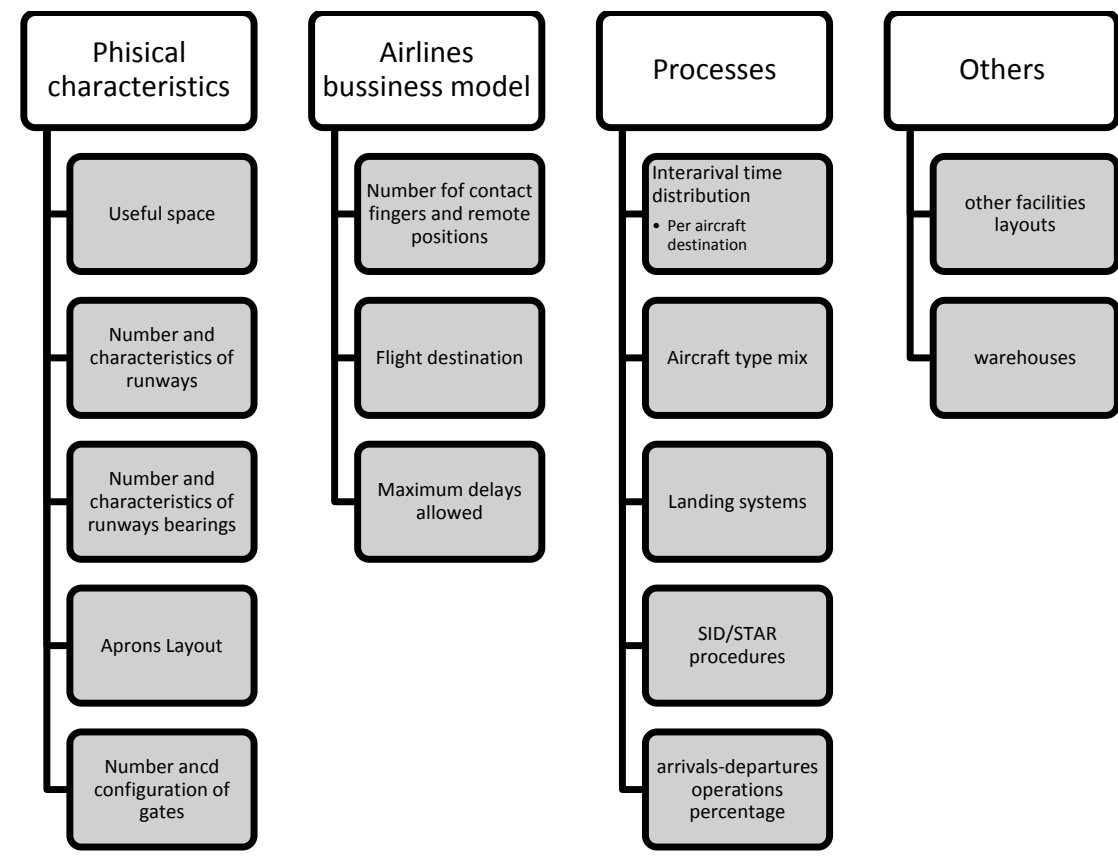

IATA/ICAO
proceures

Figure 11. Airside typical design parameters 


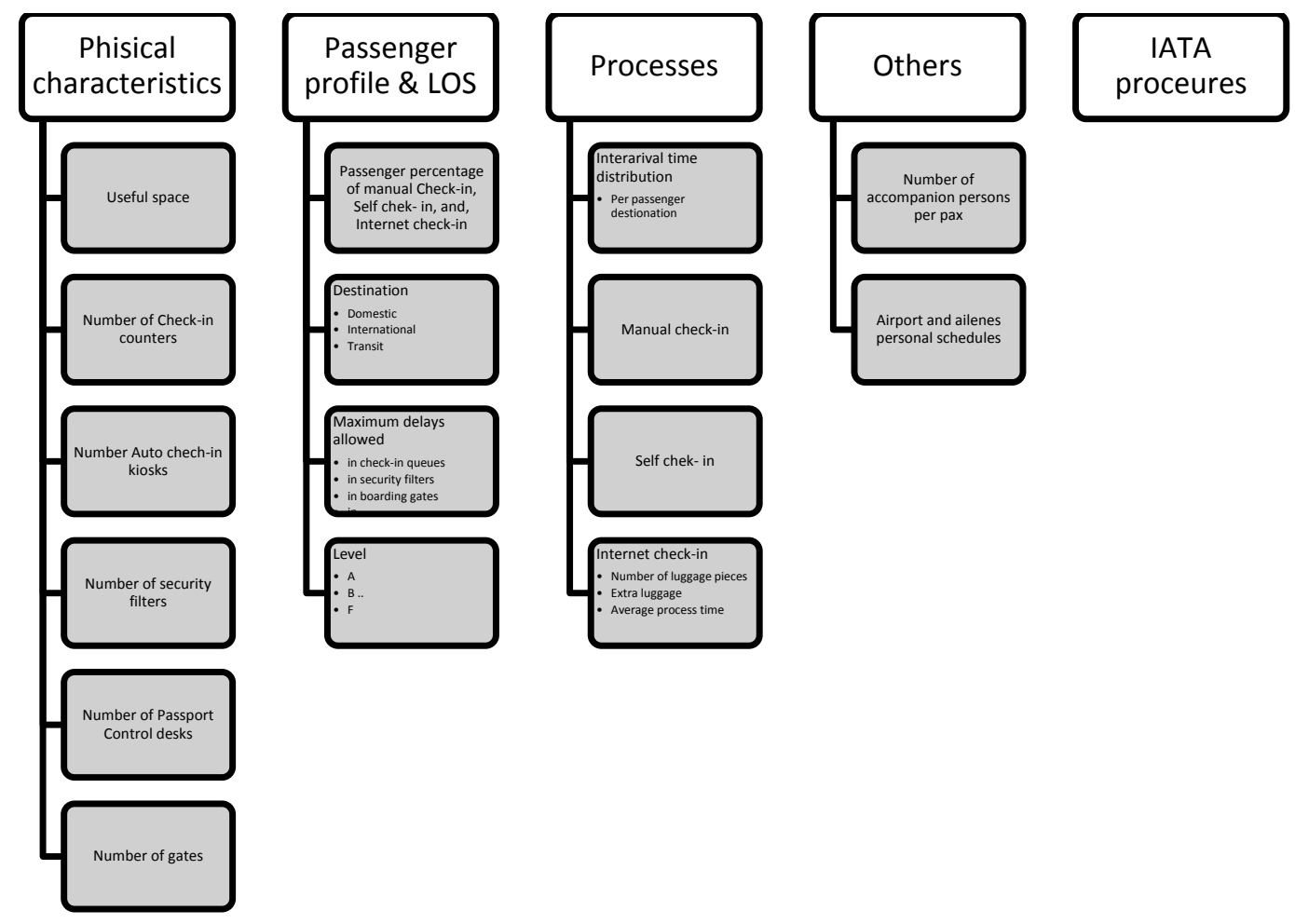

Figure 12. Landside typical design parameters

It is fundamental to define certain magnitude of level-of-service (LOS) standards that the capacity of the airport can handle with an acceptable quality. The specification of level-of-service standards aim to specify minimum standards for waiting times and space allocation, i.e. area per occupant at the processing facilities, the holding areas, and the passageways of the terminal. Hence, the LOS for space are usually defined in terms of "space conversion factors" giving the appropriate space per simultaneous occupant; it should be pointed out that higher standards imply more space and cost, which has to be compatible with the financial objectives of the airport manager. Each institution has its own standards, Table 5 and Table 6 introduces common LOS standards, (De Neufville, R., \& Odoni, A., 2003).

Table 5. Categories for Level of Service Indicators

\begin{tabular}{|l|l|l|l|l|l|l|}
\hline Subsystem & \multicolumn{7}{|c|}{ Level of Service } \\
\cline { 1 - 6 } LOS & A- Excellent & B- High & C- Good & D- Adequate & E- Inadequate & F- Unacceptable \\
\hline Flows & Free & Stable & Stable & Unstable & Unstable & System \\
\hline Delays & None & Very Few & Acceptable & Passable & Unacceptable & Breakdown \\
\hline Comfort & Excellent & High & Good & Adequate & Inadequate & \\
\hline
\end{tabular}

Table 6. Typical Values for Level of Service Indicators for Space Standard

\begin{tabular}{|l|c|c|c|c|c|}
\hline \multicolumn{1}{|c|}{ Subsystem } & \multicolumn{5}{c|}{ Level of Service } \\
\hline & A & B & C & D & E \\
\hline Wait/circulate & 2.7 & 2.3 & 1.9 & 1.5 & 1.0 \\
\hline Bag Claim & 2.0 & 1.8 & 1.6 & 1.4 & 1.2 \\
\hline Check-in Queue & 1.8 & 1.6 & 1.4 & 1.2 & 1.0 \\
\hline Hold-room Inspection & 1.4 & 1.2 & 1.9 & 0.8 & 0.6 \\
\hline
\end{tabular}


Recent works, such as the one in (FAA,2011) have evaluated appropriate level-of-service standards applied in the terminal planning and design process while testing the continued validity of historic space allocation parameters that have been in use for more than 30 years. The researchers used a new approach to measure how passengers perceive the sufficiency of space, relying on quantitative data in combination with ethnographic interviews. Interviews were conducted on site within the terminals at seven case-study airports. The research also examined what other factors might affect positive perception of level of service, such as availability of extended information resources plus opportunities for use of technology (wireless connectivity, power connections for computers and other electronic equipment, and other innovations).

Even though the LOS can be converted into space indicators, there should be no confusion about allocating space in proportion to the number of people simultaneously in any particular part of the terminal. There is a key concept when designing which is called dwell time, according to Odoni (1992) it is the amount of time spent in a particular area, which is central when determining the number of simultaneous occupants per area. The overall objective is not to provide facilities that result in a perfect match of unrestrained service levels for the peak hours but to provide a robust design that may not result in a waste of resources at other times. One of the most common mistake is to design spaces not considering the dwell time but only the number of peak hour passengers (also called typical peak hour passengers, TPHP). Therefore, a design must incorporate the time passengers actually spend in a space, i.e. their dwell time. It should be also distinguished between domestic and international traffic, for passengers, cargo and airplanes, if they are in transit or not.

In the following section, a literature review of the most prominent advances on analyzing passenger flows and to determine the amount of space and the number of servers required is presented. Essentially there are three popular approaches to do it: queuing theory; graphical analysis using cumulative diagrams; and computer simulations. Each technique presents advantages and disadvantages, queuing theory have not provided efficient designs mainly due to the processes in airports are dynamic by nature and the analytical solutions do not capture the complexity of those systems. Graphical analyses of the cumulative arrivals and service have worked effective when analyzing and designing some specific elements of the terminal such as departure and arrival lounges or ticket-counters. Simulation technique is perhaps the most robust approach to deal with the flow analysis of the terminal building. Simulation allows concentrating effort in investigating the effects of the uncertainties within the system. The appearance and development of computers as well as their systems have provided access to an endless source of tools to find alternatives for the solution of a wide variety of situations in all kinds of fields with high complexity. Thus, this resulted in the application of simulation which implies repetitive continuous experimentation without high costs, under safety environments and helpful for the training of people. Simulation approaches allows the thorough analysis and the obtainment of an individual solution for a particular problem while analytical methods only provide general ones. The application of computer simulation has allowed an easy experimentation with virtual environments with such an important level of detail even in complex problems (Banks et al, 2010).

The approach and the methodology that is embraced within this work, is the use of simulation modeling and analysis, which is quite suitable for studying passenger flow in an airport terminal. Simulation can be considered as one of the best-fit solutions for modeling and analyzing a passenger terminal for capacity analysis under varying scenarios, taking into consideration LOS and other stochastic variables since simulation can, by nature, model deterministic as well as stochastic systems. It considers the variability and the dynamic features of the system which allows the end-to-end passenger experience analysis under a variety of scenarios. 


\section{LITERATURE REVIEW}

Authors have tackled isolated each of the elements of the land and airside to enhance capacity and other as integrated systems. These works can be classified respect to three main aspects: level of detail (macroscopic and microscopic), methodology (commonly analytical and simulation models), and coverage (a single element or integrated system).

Macroscopic approaches lead to approximate answers mainly for planning purposes and some design issues, with an emphasis on assessing the relative performance of a wide range of alternatives. These kinds of approaches allow a strategic perspective, which is crucial in the current context for the major airports around the world, especially when there is not enough financial resources for taking the decision of investing in the construction of more facilities. There are few works that address the airport terminal capacity problem in a macroscopic approach. Furthermore, according to Solak (2009), there are no works which actually address the airport terminal capacity problem in a truly holistic fashion, because of the difficulty of modeling passenger flow in a complex terminal structure with transient demand patterns. It can also be found diverse literature that cover the check-in allocation, security and immigration check points, baggage carousels, customs counters, holding areas and even amenities, i.e. restrooms, restaurants, shop, banks and other facilities.

Some of the first studies (Cox and Smith, 1961; Lee, 1966) use queuing models for enplanement passenger check-in to determine the average service and wait times. This approach was used to design or redesign efficient ticketing areas, including optimum capacity and space allocation. In the work of Odoni and Neufville (1992a) it has been analyzed the entire departure lounge in an airport terminal. Other functional areas such as corridors, seating, and immigration points have been included into the analysis (De Neufville and Grillot, 1982).

Some other developed methodologies to evaluate capacity at airport terminal facilities as in Mumayiz and Ashford (1986). The authors examined 6 airport facilities check-in, security control, immigration, baggage recovery and customs control. It was constructed a model of service perception and response based on processing time using 3 LOS. It was possible to establish the relationship between passenger demand and LOS provided. The FAA (2010) has also produced techniques to evaluate capacity and formulate recommendations to measure capacity. For each facility it is offered description and demand for components, operational characteristics, and diverse methods to evaluate capacity. Within this document, the FAA provides well defined requirements and data for airport planning, design, and modeling. Other works can be the ones from Tosic (1992) and Martel and Seneviratne (1990) where surveys of researches can be found on the area of airport passenger terminal operations analysis and modeling, including applications, methods and techniques.

Other authors have focus their attention on developing analytical models and simulation tools to monitor and analyze airport operations and optimizing the airport system and network with respect to capacity and delays, as well as cost/benefit analysis see (Odoni, 1991), (Odoni et al., 1997) and (OPAL, 2003), (Andreatta et al., 1999), (Zografos and Madas, 2004) to mention some.

In relation to simulation of Mexican airports very few studies have been performed. Generally, these have been focused on Mexico City International Airport mainly modeling airside to reduce operating costs and passenger delays at runways (Herrera 2001 and 2012) and recently (Mendoza, 2015). However, this work does not consider the landside and terminal area.

The check-in allocation problem, for example, has been studied by Parlar \& Sharafali, (2013) using a dynamic programming approach. The authors find solution under some assumptions as closing or opening counters depending on the demand. Littler and Whitaker (1997) aim to estimate staffing requirements to 
meet a pre-set processing time target by means of simulation. Their approach was used as a decision support tool in the design. Park and Ahn, (2003), focus on the check-in problem at Gimpo airport to determine the most appropriate number of check-in counters. Mujica and Zuñiga (2014) employ a hybrid methodology to simulate the check-in problems using Genetic Algorithms and Discrete Event Simulation techniques. They propose an interesting methodology to address stochasticity in some variables.

Other works have focused their attention on the simulation of passenger security system as in (Penergraft, Robertson, and Shrader 2004). Their work applied the business process re-engineering approach to the passenger process. Their approach was used to provide analytical support for operational policy development of the airport. In the work of Wilson, Roe, and So (2006) the impact of new or modified airport procedures and facilities on the security effectiveness, operational costs were evaluated to provide planning and operational support.

\section{MODELING APPROACH}

Simulation represents a fruitful technique since it generates an artificial history of a system, which provides the base for inferences with regards of the operating characteristics of the real system. With that, it gives certainty on the decisions due to its correct course of action. It is broad and flexible, providing a basis for continuous improvement according to the initial results and their performance.

Simulation can be defined as a numerical technique for producing experiments in a digital computer, using graphics, animation and others technological devices; which involve some mathematic and logical models, which describe the behavior of a system (Flores et al., 2013). Simulation involves the possibility to explore new policies and procedures without disrupting ongoing operations of the real system; also new systems can be tested without committing resources for their acquisition. In that sense, the time (a very valuable resource) can be compressed or expanded with the simulation. Also the hypothesis of the researching can be tested for feasibility; and insight can be obtained about the interaction of variables. A simulation study can help in understanding how the system operates rather than how individuals think the system operates. In brief, the simulation can answer the question What if? This is useful in the design of new systems.

Simulation is used to model systems (or real-world process), which can be defined as a set of objects linked by some regular interaction or interdependence over time, concerning the consecution of some purpose. It was also established that a system is more than the sum of its parts; it is an indivisible whole. It loses its essential properties when it is taken apart. The elements of a system may themselves be systems, and every system may be part of a larger system. Every system includes other systems (called sub-systems), but at the same time the whole system is a part of a superior system (supra-system). Because of that, the interaction and interrelation between each component of a system is fundamental to understand the whole system (Banks et al, 2010), (Weiner, 2009).

On the other hand, a system is made up of the following elements: entity, attributes, activities, state of a system and event. The entity is an object or component in the system which requires explicit representation in the model. An entity can be dynamic in that it "moves" through the system, or it can be static in that it serves other entities; the attributes are properties of that entity; whereas an activity represents a time period of specified length. Other important concepts are called the states and events. A state is the collection of variables necessary to describe the system at any time, relative to the objectives of the study; these variables are called state variables; while an event is an instantaneous occurrence that may change the state of the system (Banks et al, 2010). 
According to Weiner (2009), systems can be classified depending on how the states variables and time are represented in the model as continuous and discrete. According to time base, there are continuous time paradigms, where time evolves continuously, and discrete time paradigms, where time evolves by advancing in discrete portions. On the other hand, if the values of the state variables are considered, there are continuous models, where the variables take their values from continuous set represented as a real number, and discrete models, where the variables are discrete and can be represented as a finite set of integer numbers.

Discrete Event Simulation (DES) consists of modeling a system over time with the development of changes on its state at discrete points in time. It develops after producing a sequence of system images, representing the evolution of the system through time (Banks et al, 2010). There is a large literature in the Discrete Event System (DES) field such as in (Cassandras, 2009), (Banks, 2010) and (Weiner, 2009), among others.

\section{The departure process}

The approach proposed within this work provides a model that mimics departure operations within a medium size Mexican airport, including all the departure functional areas. The departure process is illustrated through the flowchart presented in Figure 13 lla co. It starts when passengers arrive to the airport departure hall which is used to serve both, domestic and international passengers, as well as accompanying. The first process to be modeled is the check-in for both domestic and international flights. This process models passenger arrival before flight until the check-in is performed.

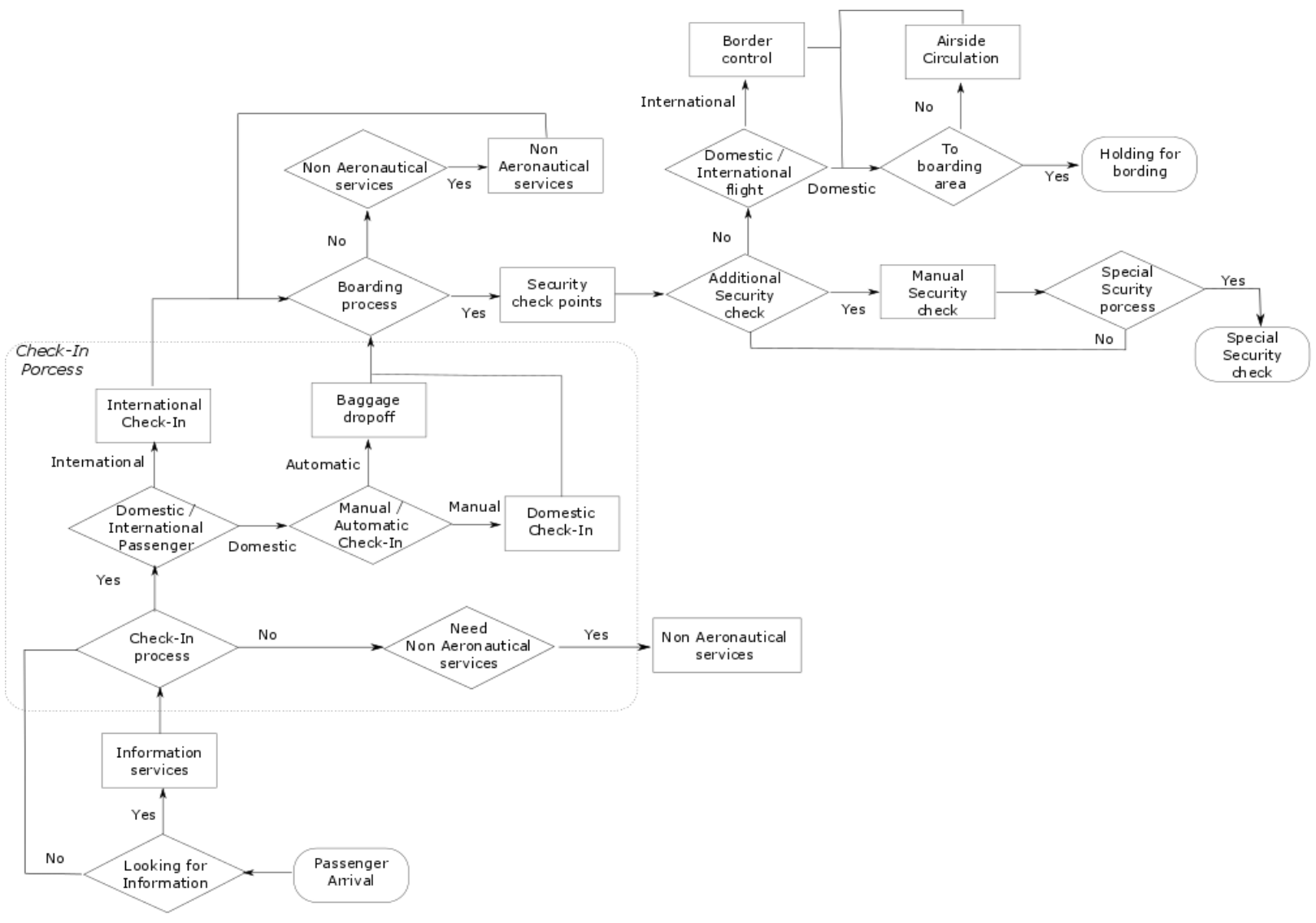

Figure 13. Passenger arrival procedure for international and domestic flights 
The proposed model can be adapted to any airport and can be filled with data for any period of time (i.e. peak or non-peak hours). Figure 14 introduces the daily arrival distribution used within this work. The simulation is executed for 1 day period but it can also be simulated for different periods i.e. one or more days, weeks, months or years of operation, depending of the planning purpose. The model of the boarding process has been developed using a general purpose simulation software called SIMIO (SIMIOweb, 2015).

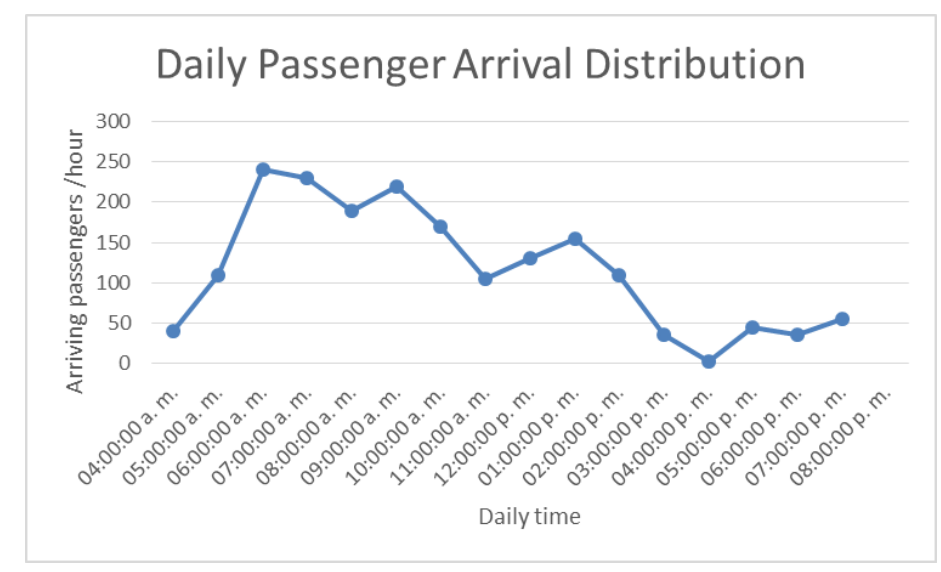

Figure 14. Typical daily passenger arrival distribution in a medium size Mexican airport

Normally, passengers and their companions arrive from a time-based arrival schedule which depends on their trip (see Figure 15 as an example). Each passenger has different characteristics such as group size, international/domestic trip destination, number of bags, and servicing airline and flight, among others.

The arrival profiles of the passengers have been taken as three different types: business, tourist and special passengers since the objective of the work only is to present the approach for supporting decisions in operation planning. Each type of passenger arrival has been modeled with a discrete distribution of $30 \%$ for business arrival, $50 \%$ of tourist and $15 \%$ for special passengers. According to (Schultz, 2011), the movement behavior mainly depends on passengers characteristics such as baggage (e.g. trolley, baggage cart, or rucksack), gender, group size and travel purpose (business or tourist), among others. Hence an average normal distribution has been taken for each kind of the three passengers modeled, see Table 7.

Table 7. Speed profiles for different passenger types

\begin{tabular}{|l|l|}
\hline \multicolumn{1}{|c|}{ Passenger type } & \multicolumn{1}{c|}{$\begin{array}{c}\text { Speed } \\
(\boldsymbol{m} / \mathbf{s})\end{array}$} \\
\hline 1: Business & Uniform $(0.4,0.5)$ \\
\hline 2: Tourist & Uniform $(0.3,0.9)$ \\
\hline 3: Special passenger & Uniform $(0.7,1.2)$ \\
\hline
\end{tabular}

To locate the corresponding check-in counter it can be used the flight information desk or display screens. The check-in area might be composed by manual check-in or automatic (self-service check-in/online check-in) and baggage drop to complete the check-in process. 14 manual ticketing counters and 3 automatic ones (kiosks) have been modeled. Passengers are routed to their respective desks based on their characteristics, i.e. servicing airline, destination, and corresponding class and flight desk. Furthermore, passengers can choose between manual and automatic ticketing to perform their check-in process. For domestic flights, both options are normally available, but for international ones, it should be performed 
normally a manual check-in. The manual check-in includes baggage acceptance, security questions, documentation checks, boarding card issue, and gate information. In most of the flights, there is a preferential desks(s), for first class, business or special travelers. The automatic check-in includes documentation checks, boarding card issue, and gate information, the baggage drop-off has to be performed in a special desk or machine.

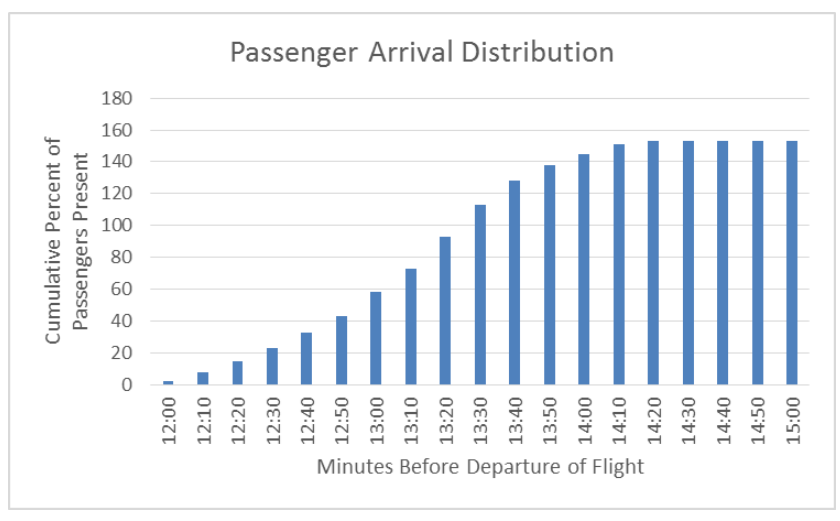

Figure 15. Example of passenger arrival distribution in an international flight

The check-in area might be composed by manual check-in or automatic (self-service check-in/online check-in) and baggage drop to complete the check-in process, see Figure 16. Passengers are routed to their respective desks based on its characteristics, i.e. servicing airline, destination, and corresponding class and flight desk. Furthermore, passengers can choose between manual and automatic ticketing to perform their check-in process if they are taking a domestic flight, but for international passengers, the process should be performed within manual check-in. The manual check-in includes baggage acceptance, security questions, documentation checks, boarding card issue, and gate information. In most of the flights, there is a preferential desks(s), for first class, business or special travelers. The automatic check-in includes documentation checks, boarding card issue, and gate information, the baggage drop-off has to be performed in a special desk or machine.

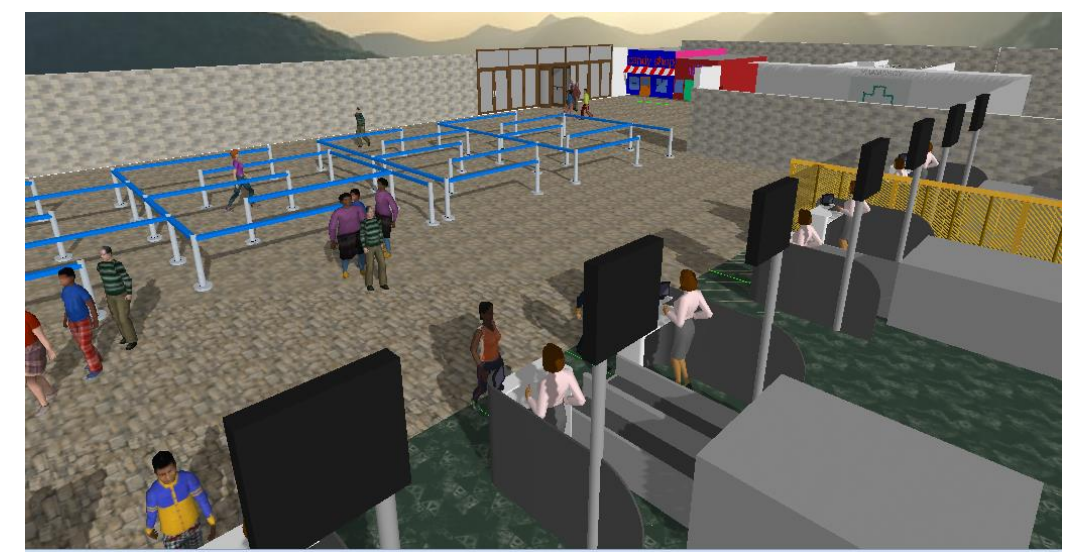

Figure 16. Snapshot or check-in process

Table 8 show some simulation parameters employed in the model. Data was taken from the work of (Siroky, 2014). It is introduced the service time and probability that passengers use the different services available, i.e. information desk, leisure services or passengers to direct to the check-in process and the arrival distribution expression of time spend within each service. 


\begin{tabular}{|l|l|l|l|l|}
\hline \multicolumn{2}{|c|}{$\begin{array}{c}\text { Probability to use a } \\
\text { specific service }\end{array}$} & \multicolumn{3}{c|}{ Service time (min) } \\
\hline & & \multicolumn{1}{c|}{ Business } & \multicolumn{1}{c|}{ Tourist } & \multicolumn{1}{c|}{ Special } \\
\hline Information desk & 35 & Triangular(0.4,1,2) & Triangular(0.8,3,5) & Triangular(1,4,8) \\
\hline Shops & 10 & Triangular(1,3,5) & Triangular(3,6,10) & Triangular(10,15,25) \\
\hline $\begin{array}{l}\text { Restrooms \& } \\
\text { phones }\end{array}$ & 10 & Triangular(2,3,4) & Triangular(2.5,3,5) & Triangular(3,5,10) \\
\hline Restaurants & 10 & Triangular(0,7,15) & Triangular(5,30,60) & Triangular(20,30,60) \\
\hline Waiting area & 50 & Triangular(15,25,40) & Triangular(20,45,60) & Triangular(30,45,60) \\
\hline Manual check-in & 80 & Lognormal(3,0.25) & Lognormal(4.05,0.45) & Lognormal(6.058,0.50) \\
\hline $\begin{array}{l}\text { Automatic } \\
\text { check-in }\end{array}$ & 20 & Gamma(5,2) & Gamma(14.37,2.29) & Gamma(19.7,3) \\
\hline Baggage drop-off & & Lognormal(2,0.2) & Lognormal(2.39,0.25) & Lognormal(4,0.5) \\
\hline Security check & 100 & Gamma(5,1) & Gamma(14.37,2.29) & Gamma(20,2) \\
\hline X-ray screening & 100 & Exponential(0.02) & Exponential(0.0464) & Exponential(0.06) \\
\hline $\begin{array}{l}\text { Immigration } \\
\text { checkpoint }\end{array}$ & 30 & Triangular(10,15,20) & Triangular(15,20,25) & Triangular(15,20,25) \\
\hline
\end{tabular}

At any moment before the security points, passengers can use other supplementary facilities and services such as restrooms, banks, shops, telephones, catering facilities (restaurants, cafe, bars, etc.), children's play areas, leisure areas, baggage trolleys, information counters, airline customer service, sales desk, etc. which are located in the public common area, see Figure 17. There are also special passenger-handling services and facilities which can be used for passengers with reduced mobility and unaccompanied minors.

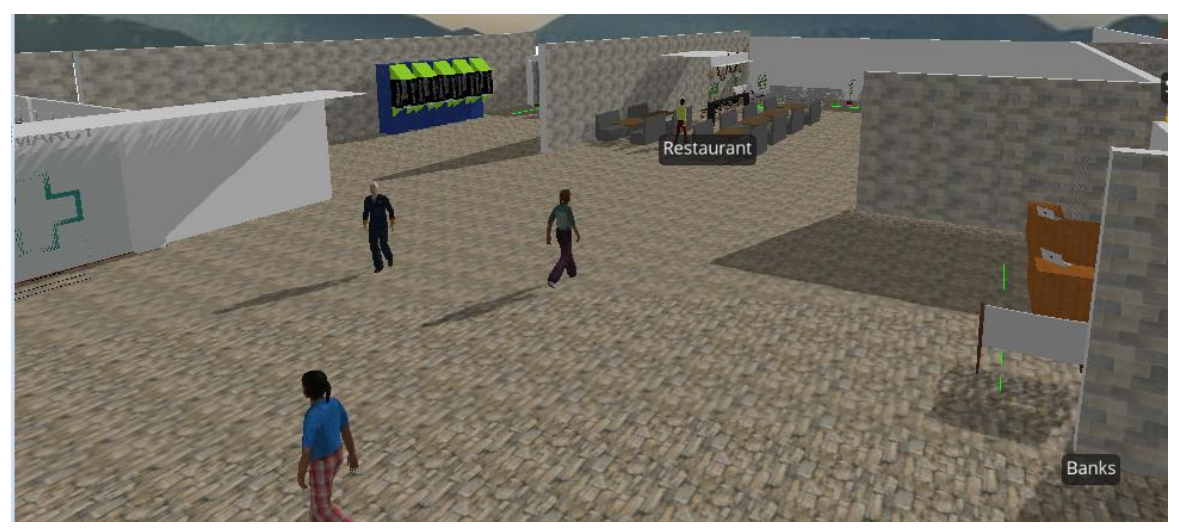

Figure 17. General services provided for passengers

After check-in, passengers should go to security screening checkpoints to enter the area for boarding. The security checkpoint is typically composed of a combination of regular lanes and employee lanes, see Figure 18. In our case, two regular lanes and two scanning devices have been modeled. This area also includes preceding queuing area, individual queues, carry-on luggage drop off, scanning devices, and bag pick up. One of the main objectives of the luggage inspections and physical screening is to prevent airplane hijacking, therefore there are some prohibited or restricted items and liquids in the carry-on luggage. It is normally asked to passengers to show their boarding pass and passport to the security staff 
and put them onto the carry-on luggage or bins. Within this process, passengers are asked to leave their carry-on luggage at the special counter lines and to remove small objects from them (keys, wallet, cell phone, scarf, etc.) and place them either in their carry-on luggage or in a tray to be screening. Once all objects are removed, the passenger can join the line and are asked to walk through the metal detector, if it is necessary, a physical or manual screening could be performed.

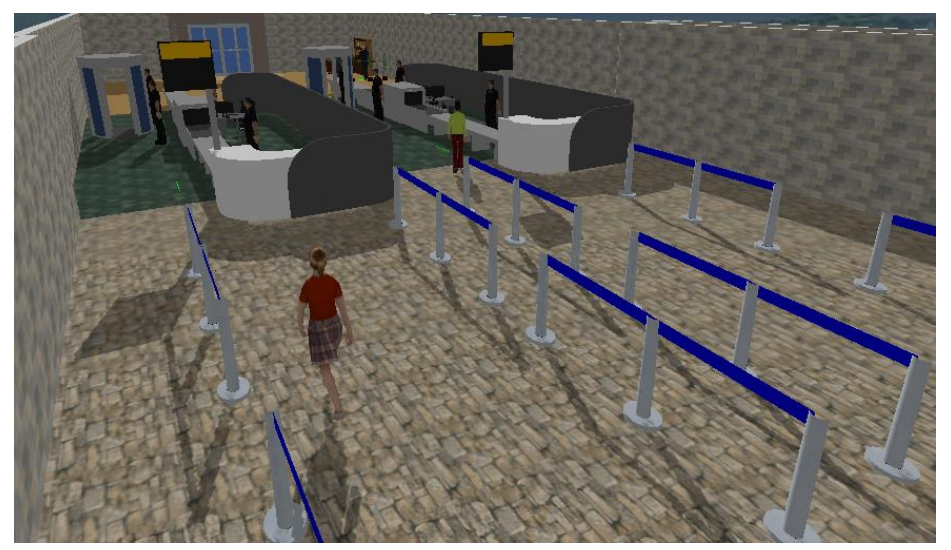

Figure 18. Security control points

In the case that the passenger will perform an international flight, an immigration control procedure must be carried out by the immigration border control police. International passengers are asked to show their proper immigration documents and to answer some questions to verify their destination, among other tasks. If the passenger is consider "clean" he can continue his path to the waiting area. Figure 19 depicts the four border control counters modeled within this work.

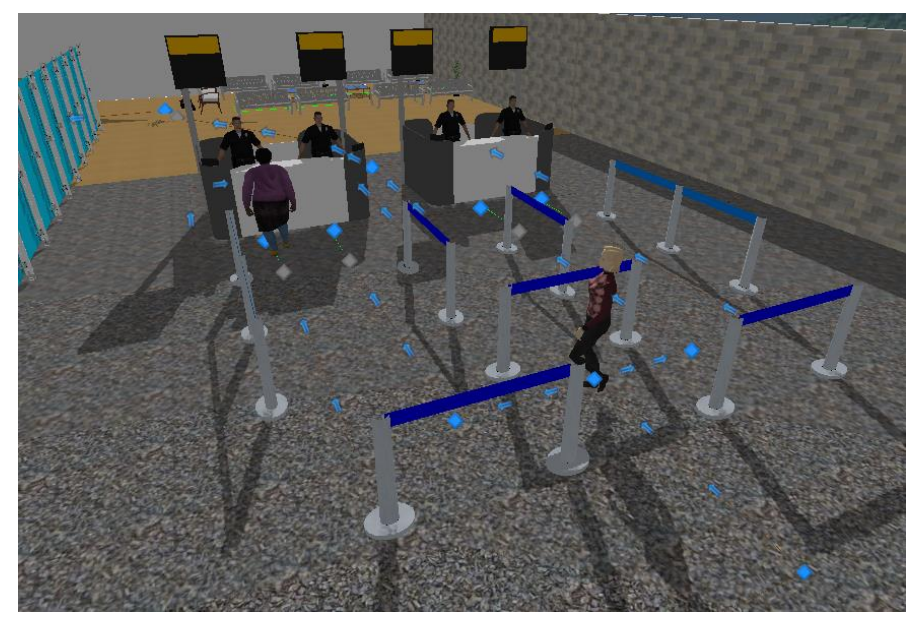

Figure 19. Immigration control points

Regarding the terminal building for commercial flights, it has an area of $200 \mathrm{~m} 2$. The layout, it is depicted in Figure 20. It can be noticed that each area has been label with the proper process which is performed. At the right side of the entrance, it is located the check in area which is $14 \times 6 \mathrm{~m}$; the general nonaeronautical services are located straight ahead of entrance in an area of 7x6 m. The security area is an area of $6 \times 4 \mathrm{~m}$ and immigration is $6 \times 5 \mathrm{~m}$. 
The first scenario to be tested corresponds to data obtain from a sample day at a Mexican airport, which includes 5 airlines and 17 flights in a typical day. Table 9 introduces the flights considered as well as destination and schedule date. A second scenario has been introduced modeling 3 more flights with a total of 250 passengers to test the behavior of the system under the growing demand predicted by the Mexican aeronautical organization, see Table 10. It has been marked in red the inclusion of 3 flights in a single day. In both scenarios, check-in desk have been assigned in the following way: Aeromexico performs its check-in activity in desk 1 to 4; United Airlines in desk 5 and 6; TAR in desk 7 and 8; American Airlines desk 9 to 12; and Volaris desks 13 and14. For domestic flights each check-in is opened 2 hours prior the departure and for international ones three hours.

Figure 20. Airport layout.

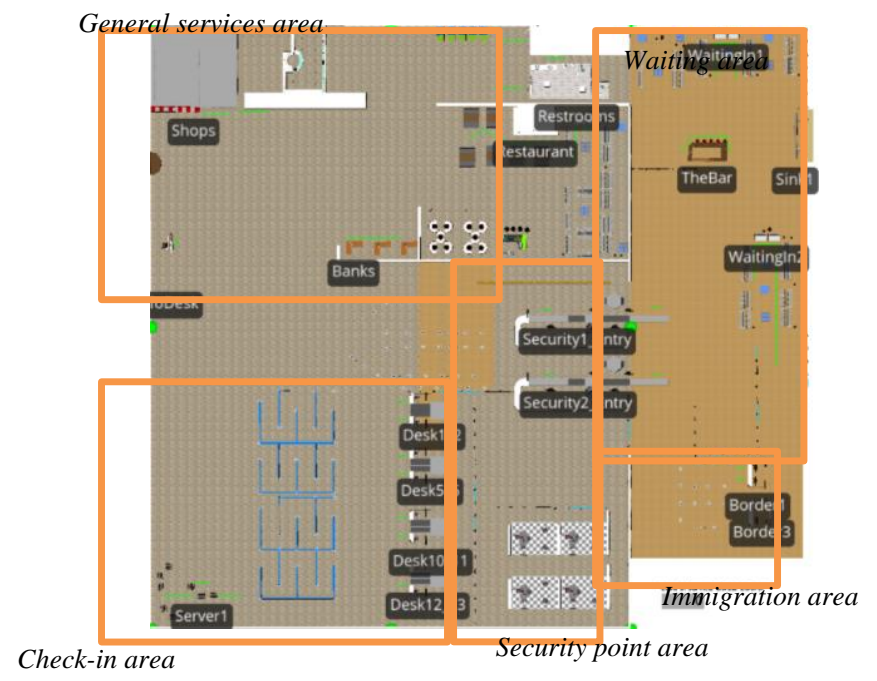

Table 9 Scenario I

\begin{tabular}{|l|l|l|l|l|l|}
\hline \multicolumn{1}{|c|}{ Airlines } & Flight & From & \multicolumn{1}{|c|}{ To } & \multicolumn{1}{c|}{ Scheduled } & \multicolumn{1}{c|}{$\begin{array}{c}\text { Passengers } \\
\text { per flight }\end{array}$} \\
\hline Aeromexico & 2237 & Querétaro & Monterrey & 06:10:00 a. m. & 60 \\
\hline TAR & LCT-764 & Querétaro & Monterrey & 06:45:00 a. m. & 50 \\
\hline United Airlines & 5216 & Querétaro & Houston & 06:50:00 a. m. & 90 \\
\hline American Airlines & 5788 & Querétaro & Dallas & 07:15:00 a. m. & 60 \\
\hline Aeromexico & 2264 & Querétaro & Monterrey & 08:02:00 a. m. & 50 \\
\hline Volaris & 207 & Querétaro & Monterrey & 09:45:00 a. m. & 50 \\
\hline TAR & LCT-432 & Querétaro & Guadalajara & 10:10:00 a. m. & 50 \\
\hline United Airlines & 4483 & Querétaro & Houston & 11:43:00 a. m. & 100 \\
\hline Volaris & 847 & Querétaro & Tijuana & 12:20:00 p. m. & 50 \\
\hline American Airlines & 5780 & Querétaro & Dallas & 01:49:00 p. m. & 100 \\
\hline Volaris & 112 & Querétaro & Cancun & 01:51:00 p. m. & 60 \\
\hline United Airlines & 5217 & Querétaro & Houston & 02:19:00 p. m. & 80 \\
\hline TAR & LCT-762 & Querétaro & Monterrey & 02:30:00 p. m. & 50 \\
\hline Aeromexico & 2226 & Querétaro & Monterrey & 03:15:00 p. m. & 60 \\
\hline TAR & LCT-500 & Querétaro & Acapulco & 04:15:00 p. m. & 50 \\
\hline TAR & LCT-766 & Querétaro & Monterrey & 06:55:00 p. m. & 50 \\
\hline Aeromexico & 2268 & Querétaro & Monterrey & 08:10:00 p. m. & 50 \\
\hline
\end{tabular}


Table 10 Scenarios II

\begin{tabular}{|l|l|l|l|l|l|}
\hline \multicolumn{1}{|c|}{ Airlines } & \multicolumn{1}{|c|}{ Flight } & \multicolumn{1}{|c|}{ From } & \multicolumn{1}{|c|}{ To } & \multicolumn{1}{|c|}{$\begin{array}{c}\text { Passengers } \\
\text { per flight }\end{array}$} \\
\hline Aeromexico & 2237 & Querétaro & Monterrey & 06:10:00 a. m. & 60 \\
\hline TAR & LCT-764 & Querétaro & Monterrey & 06:45:00 a. m. & 50 \\
\hline United Airlines & 5216 & Querétaro & Houston & 06:50:00 a. m. & 90 \\
\hline American Airlines & 5788 & Querétaro & Dallas & 07:15:00 a. m. & 60 \\
\hline Aeromexico & 2264 & Querétaro & Monterrey & 08:02:00 a. m. & 50 \\
\hline Volaris & 111 & Querétaro & Mexico city & 08:20:00 p. m. & 80 \\
\hline Volaris & 207 & Querétaro & Monterrey & 09:45:00 a. m. & 50 \\
\hline TAR & LCT-432 & Querétaro & Guadalajara & 10:10:00 a. m. & 50 \\
\hline United Airlines & 4483 & Querétaro & Houston & $11: 43: 00$ a. m. & 100 \\
\hline Volaris & 847 & Querétaro & Tijuana & $12: 20: 00$ p. m. & 50 \\
\hline American Airlines & 5780 & Querétaro & Dallas & 01:49:00 p. m. & 100 \\
\hline Volaris & 112 & Querétaro & Cancun & 01:51:00 p. m. & 60 \\
\hline United Airlines & 5217 & Querétaro & Houston & 02:19:00 p. m. & 80 \\
\hline TAR & LCT-762 & Querétaro & Monterrey & 02:30:00 p. m. & 50 \\
\hline Aeromexico & 2226 & Querétaro & Monterrey & 03:15:00 p. m. & 60 \\
\hline TAR & LCT-500 & Querétaro & Acapulco & 04:15:00 p. m. & 50 \\
\hline TAR & LCT-766 & Querétaro & Monterrey & 06:55:00 p. m. & 50 \\
\hline Aeromexico & 2268 & Querétaro & Monterrey & 08:10:00 p. m. & 50 \\
\hline United Airlines & 5217 & Querétaro & Miami & 08:50:00 p. m. & 90 \\
\hline Volaris & 111 & Querétaro & Mexico city & 08:20:00 p. m. & 80 \\
\hline
\end{tabular}

\section{RESULTS}

The output report of both simulation scenarios (I and II) presented in the previous section are presented within this section. Table 11 shows diverse key performance indicators (KPIs) such as waiting time in each resource and percentage of utilization. As an example, the reader must pay attention at the resource called "desk1" which refers, as it names indicates, to check-in counter \#1. It reports a utilization of 73\% and passengers that have to wait in it in average spend 0.056 hrs. The most congested desk is Desk 7 which is used by TAR airlines.

Table 11 KPIs numerical results from scenario I

\begin{tabular}{|l|l|l|l|l|}
\hline \multicolumn{1}{|c|}{ Resource } & $\begin{array}{c}\text { Utilization } \\
(\%)\end{array}$ & \multicolumn{3}{c|}{$\begin{array}{c}\text { Pax Time } \\
\text { (hrs) }\end{array}$} \\
\hline \multicolumn{5}{|c|}{ Check-in desks } \\
\hline & Average & Average & Minimum & Maximum \\
\hline Desk1 & 73 & 0.056 & 0.055 & 0.056 \\
\hline Desk2 & 72 & 0.053 & 0.054 & 0.056 \\
\hline Desk3 & 79 & 0.057 & 0.056 & 0.059 \\
\hline Desk4 & 75 & 0.056 & 0.056 & 0.058 \\
\hline
\end{tabular}




\begin{tabular}{|c|c|c|c|c|}
\hline Desk5 & 80 & 0.061 & 0.063 & 0.068 \\
\hline Desk6 & 85 & 0.065 & 0.066 & 0.069 \\
\hline Desk7 & 87 & 0.066 & 0.068 & 0.072 \\
\hline Desk8 & 86 & 0.065 & 0.068 & 0.070 \\
\hline Desk9 & 65 & 0.044 & 0.047 & 0.048 \\
\hline Desk10 & 52 & 0.040 & 0.041 & 0.042 \\
\hline Desk11 & 57 & 0.041 & 0.042 & 0.043 \\
\hline Desk12 & 61 & 0.042 & 0.046 & 0.0047 \\
\hline Desk13 & 73 & 0.056 & 0.056 & 0.058 \\
\hline Desk14 & 78 & 0.047 & 0.051 & 0.053 \\
\hline \multicolumn{5}{|c|}{ Security checkpoints } \\
\hline Security Counter 1 & 67 & 0.083 & 0.083 & 0.083 \\
\hline Security Counter 2 & 65 & 0.086 & 0.086 & 0.088 \\
\hline Security Scan 1 & 25 & 0.0030 & 0.0030 & 0.0031 \\
\hline Security Scan 2 & 29 & 0.0041 & 0.0041 & 0.0042 \\
\hline \multicolumn{5}{|c|}{ Border control checkpoints } \\
\hline Border Counter 1 & 53 & 0.044 & 0.044 & 0.044 \\
\hline Border Counter 2 & 42 & 0.043 & 0.044 & 0.046 \\
\hline Border Counter 3 & 49 & 0.042 & 0.045 & 0.045 \\
\hline Border Counter 4 & 45 & 0.041 & 0.043 & 0.043 \\
\hline \multicolumn{5}{|c|}{ Inside waiting area } \\
\hline Waiting area 1 & 85 & 0.45 & 0.45 & 0.49 \\
\hline Waiting area 2 & 87 & 0.56 & 0.58 & 0.52 \\
\hline
\end{tabular}

Different LOS indicators have also been evaluated using the simulation model for the check-in area, the security checkpoint, immigration checkpoint and waiting areas. Table 12 presents the results obtained.

Table 12 LOS numerical results from scenario I

\begin{tabular}{|l|l|l|l|}
\hline & Average & Minimum & Maximum \\
\hline Check-in LOS & 11.81 & 9.5 & 15.8 \\
\hline Security LOS & 19.65 & 16.2 & 24.21 \\
\hline Border LOS & 22.15 & 19.54 & 27.19 \\
\hline
\end{tabular}

Due to the increment forecasted by authorities, other scenario has been introduced (see Table 10). The output report is presented in Table 13 and Table 14 . The same KPIs have been presented in order to be able to compere the behavior of the model. Meanwhile desk 13 and 14 in scenario I present a $73 \%$ and $78 \%$ of utilization (respectively), in scenario II it is used $75 \%$ and $85 \%$ of the time, respectively; and passengers have to wait in average 0.049 and $0.055 \mathrm{hrs}$, respectively, to be serviced. The other case is presented due to the increment to this flights corresponds to desk \#5 and \#6, belonging to United airline which, due to the new international flights, has been used $89 \%$ and $85 \%$ of time (respectively) and passengers have to wait 0.064 and $0.063 \mathrm{hrs}$, respectively, on average. 
Table 13 KPIs numerical results from scenarios II

\begin{tabular}{|c|c|c|c|c|}
\hline Resource & Utilization (\%) & \multicolumn{3}{|c|}{$\begin{array}{c}\text { Pax Time } \\
\text { (hrs) }\end{array}$} \\
\hline \multicolumn{5}{|c|}{ Check-in desks } \\
\hline & & Average & Minimum & Maximum \\
\hline & Average & Average & Minimum & Maximum \\
\hline Desk1 & 73 & 0.056 & 0.055 & 0.056 \\
\hline Desk2 & 72 & 0.053 & 0.054 & 0.056 \\
\hline Desk3 & 79 & 0.057 & 0.056 & 0.059 \\
\hline Desk4 & 75 & 0.056 & 0.056 & 0.058 \\
\hline Desk5 & 89 & 0.064 & 0.066 & 0.075 \\
\hline Desk6 & 85 & 0.063 & 0.071 & 0.073 \\
\hline Desk7 & 87 & 0.066 & 0.068 & 0.072 \\
\hline Desk8 & 86 & 0.065 & 0.068 & 0.070 \\
\hline Desk9 & 65 & 0.044 & 0.047 & 0.048 \\
\hline Desk10 & 52 & 0.040 & 0.041 & 0.042 \\
\hline Desk11 & 57 & 0.041 & 0.042 & 0.043 \\
\hline Desk12 & 75 & 0.049 & 0.051 & 0.0055 \\
\hline Desk13 & 81 & 0.057 & 0.059 & 0.062 \\
\hline Desk14 & 85 & 0.054 & 0.055 & 0.065 \\
\hline \multicolumn{5}{|c|}{ Security checkpoints } \\
\hline Security Counter 1 & 67 & 0.083 & 0.083 & 0.083 \\
\hline Security Counter 2 & 65 & 0.086 & 0.086 & 0.088 \\
\hline Security Scan 1 & 25 & 0.0030 & 0.0030 & 0.0031 \\
\hline Security Scan 2 & 29 & 0.0041 & 0.0041 & 0.0042 \\
\hline \multicolumn{5}{|c|}{ Border control checkpoints } \\
\hline Border Counter 1 & 53 & 0.044 & 0.044 & 0.044 \\
\hline Border Counter 2 & 42 & 0.043 & 0.044 & 0.046 \\
\hline Border Counter 3 & 49 & 0.042 & 0.045 & 0.045 \\
\hline Border Counter 4 & 45 & 0.041 & 0.043 & 0.043 \\
\hline \multicolumn{5}{|c|}{ Inside waiting area } \\
\hline Waiting area 1 & 85 & 0.45 & 0.45 & 0.49 \\
\hline Waiting area 2 & 87 & 0.56 & 0.58 & 0.52 \\
\hline
\end{tabular}

Table 14 LOS numerical results from scenarios II

\begin{tabular}{|c|c|c|c|}
\hline & Average & Minimum & Maximum \\
\hline Check-in LOS & 10.1 & 8.87 & 13.8 \\
\hline Security LOS & 17.56 & 14.58 & 21.59 \\
\hline Border LOS & 19.89 & 17.58 & 24.58 \\
\hline
\end{tabular}


The LOS values help to decide if space utilization in peak hours is adequate. In our example, within the check-in area, in Scenario I, a minimum of $9.5 \mathrm{~m} 2 / \mathrm{pax}$ has been accounted meanwhile in Scenario II the space is reduced to $8.87 \mathrm{~m} 2 / \mathrm{pax}$. It indicates that the space in the check-in area will decrease around 0.63 $\mathrm{m} 2 /$ pax in peak hours. According to Table 5. , it places the service of both scenarios as level "A" meaning that the comfort and level of service is excellent, delays are not expected and the flow of passengers will be excellent within this area.

Analogous, the security checkpoints area has also been affected changing the available space from 19.65 $\mathrm{m} 2 /$ pax to $17.56 \mathrm{~m} 2 /$ pax. However, this decrement of space does not affect passenger's LOS, comfort and flows. Immigration checkpoints space decrement is not really meaningful respect to the LOS, mainly due to the nature of the new flights, i.e. only one out of three new flights is international.

In our example, the decision makers will approve the expected incoming flights because they will not decrease the level of service at the airport. Furthermore, it could be inspected new scenarios with bigger flight demand or new incoming flights. Nevertheless, the common areas have to be revisited integrating the departure process to have a complete overview of the behavior of the system.

\section{CONCLUSIONS}

Air transport contributes to sustainable development worldwide not only due to the transportation of tourists and freight which moved 3.3 billion people and 50 million metric tons in 2014, but also because it provides direct and indirect jobs which in turn generate economic growth in a regional and domestic scale, to be precise $\$ 2.2$ trillion USD in 2012. In the same way, it develops social and economic networks that will have long-lasting effects and closer relationships between countries, both from an individual perspective and at a country level. It improves living standards and facilitates the international trade as it has been demonstrated. All over the world, it offers a vital lifeline to communities that lack adequate road or rail networks. Summarizing, air transport is a vital component of modern life.

The traffic growth tendencies are quite favorable to the industry and all its different airspace users all over the world. As an example it can be pointed out the Asian-Pacific region that in 2032 is forecasted to account half of the fleet in the world. Nevertheless, the bigger demand and greater connectivity have to properly address to bring its benefits for the industry. Specially, in the commercial sector, the use of different and innovative airport management strategies is essential to use efficiently valuable corporate resource while meeting the growing demand of the diverse airspace users.

It has been said that all the airport network will grow doubling the number of mega-cities around the world and moving daily around 2.3 million passengers. In Mexico, the principal airport, Mexico City International Airport, is already suffering the consequences of this non stopping increasing demand. The government recently announced a project to build a new one to replace the older airport, it is and will be needed to provide decentralized strategies together with a deep analysis of the rest of the network.

Our proposed approach provides a model that generically mimics the departure process in a medium size airport, which is the case of more than the $90 \%$ of the Mexican airports. Most of the functional areas and operations within the departure process have been included. The most 
important KPIs together with the LOS indicators have been analyzed to highlight the benefits of this approach. The variable nature of airport operations make suitable the used of discrete event simulation to perform the analysis. It provides meaningful information in a timely and efficient manner.

As the purpose of this work was to show the benefits of the approach, lot of work can be done as future research, starting by applying real data from a case study, and analyzing more deeply the results obtained. A broader forecast can be employed in order to design the scenarios and different KPIs can be implemented.

\section{REFERENCES}

ACI, (2012). World Airport Traffic Report. Airport Council International.

ACI, (2013). World Airport Traffic Report. Airport Council International.

AIRBUS (2014) Global Market Forecast 2015-2034. Flying on Demand Deutsche Bank Toulouse, 22nd, January 2015.

Andreatta, G., Brunetta, L., Odoni, A.R., Righi, L., Stamatopoulos, M.A., and Zografos, K.G. (1999), "A Set of Approximate and Compatible Models for Airport Strategic Planning on Airside and Landside", Air Traffic Control Quarterly, 7 (4), pp. 291-319.

ATAG, 2012. Aviation benefits beyond borders. Air Transport Action Group. http://www.atag.org/, consultado en agosto de 2015.

Banks, J., Carson, J. S., \& Nelson, B. L. (2010), Discreet Event System Simulation, 5th Edition, Pretince Hall, United States.

Belobaba, P., Odoni, A., \& Barnhart, C. (Eds.). (2009). The global airline industry (Vol. 23). John Wiley \& Sons.

Cassandras, G.C. Lafortune S., (2009). Introduction to discrete event systems. Springer.

De Neufville R and Grillot M (1982). Design of pedestrian space in airport terminals. JTransport Eng 108: 87-102.

De Neufville, R., \& Odoni, A. (2003). Airport Systems. Planning, Design and Management. McGrawHill Education LLC.

EUROCONTROL 2013. Challenges of Growth 2013 Task 4: European Air Traffic in 2035. Technical report.

Federación Mexicana de la Industria Aeroespacial (FEMIA), 2012. Pro-Aéreo: Programa Estratégico de la Industria Aeroespacial. 
Federal Aviation Administration (FAA), (2001). Forecasting aviation activity by airport. Federal Aviation Administration, technical report.

Federal Aviation Administration (FAA), 2010. Airport Passenger Terminal Planning and Design. Volume 1: Guidebook, Office of Oper. Research, Federal Aviation Administration, Washington, DC.

Flores, I., Figueras J., Guasch A., Mujica, M., Narciso, M., Piera, M. (2013), Simulation Models: Using Simio and Preti Nets, Universidad Nacional Autonoma de Mexico, Mexico.

Herrera García Alfonso. (2001). Simulación de operaciones aeroportuarias. El caso de despegues y aterrizajes en el Aeropuerto Internacional de la Ciudad de México. Publicación Técnica No. 180, Instituto Mexicano del Transporte. México.

Herrera García Alfonso. (2012). Modelo de simulación de operaciones aéreas en aeropuertos saturados. El caso del Aeropuerto Internacional de la Ciudad de México. Publicación Técnica No. 365, Instituto Mexicano del Transporte. México.

Mendoza, E. Zuñiga, C.A., Mujica, M.A., Delahaye, D., 2015, Simulating Airport Capacity: Mexico City Airport Case. Conferences in Air Transport \& Operations. in Proceeding of the 3rd International Conference on Interdisciplinary Science for Innovative Air Traffic Management (ISIATM2015), Netherlands July, 20-23 2015.

International Air Transport Association (IATA), 2011. Vision 2050. Technical report. Singapore. International Air Transport Association (IATA), 2013 Annual Review 2013. Technical report 69th Annual General Meeting Cape Town.

International Civil Aviation Organization (ICAO), 2013. Caribbean/South American Regional Traffic Forecasts 2011-2031. Report of the Ninth Meeting. Of the CAR/SAM Traffic. Forecasting Group (CAR/SAM TFG).

M. Parlar, B. Rodrigues, and M. Sharafali. On the allocation of exclusive-use counters for airport checkin queues: static vs. dynamic policies. OPSEARCH, 50(3):433-453, 2013.

Mujica, M.A. Zuñiga, C.A.., 2015 Allocation of Airport Check-in Counters Using a SimulationOptimization Approach. In Mujica, M.A.., De La Mota-Flores, I., Guimarans-Serrano, D. (Eds.) Applied Simulation and Optimization: In Logistics, Industrial and Aeronautical Practice. pp. 203-229 Springer International Publishing. ISBN 978-3-319-15032-1

Mumayiz, S. Ashford, N., 1986. Methodology for planning and operations management af airport terminal facilities. Transportation Research Records 1094, 24-35.

Odoni AR and De Neufville R (1992a). Passenger terminal design. Transport Res Part A: Pol Pract 26(1): 27-35. 
Odoni AR and De Neufville R (1992b). Walking distance minimization for airport terminal configurations. Transport Res Part A: Pol Pract 26(1): 59-74.

Odoni, A.R. (1991), Transportation modeling needs: airports and airspace, Volpe domestic Transportation Systems Center, Cambridge, MA, USA.

OPAL Consortium (2003a), Inventory of Airport Performance Models, Technical WP1 Report - Public Version, Optimisation Platform for Airports including Landside (OPAL) Research Project funded by the European Commission (Directorate-General Energy and Transport - DG-TREN), European Commission, Brussels, Belgium.

Pendergraft, D. R., C.V. Robertson, and S. Shrader. 2004. Simulation of an airport passenger security system. In Proceedings of the 2004 Winter Simulation Conference, eds. R .G. Ingalls, M. D. Rossetti, J. S. Smith, and B. A. Peters, 874-878.

R.A. Littler and D. Whitaker. Estimating staffing requirements at an airport terminal.Journal of the Operational Research Society, 48(2):124131, 1997.

Schultz, M., Fricke, H., 2011 Managing Passenger Handling at Airport Terminals. Individual-based Approach for Modeling the Stochastic Passenger Behavior. Ninth USA/Europe Air Traffic Management Research and Development Seminar (ATM2011)

Secretaria de Comunicaciones y Transportes, (SCT) 2015. Estadística histórica (1992-2014) / Historical statistics (1992-2014).

SIMIO HOMEpage: http://www.simio.com

Siroky, J., Hlavsová, P. 2014 Optimizing process of check-in and security check at airport terminals.

Tosic, V. (1992), “A review of airport passenger terminal operations analysis and modeling”, Transportation Research Part A, 26 (1), pp. 3-26.

Wang, P. T., \& Pitfield, D. E. (1999). The derivation and analysis of the passenger peak hour: an empirical application to Brazil. Journal of Air Transport Management, 5(3), 135-141.

Weiner, G.A., (2009), Modeling and Simulation: A practitioner approach, CR Press, United States.

Wilson, D., E. K. Rose, and A. A. So. 2006. Security checkpoint optimizer (SCO): An application for simulating the operations of airport security checkpoints. In Proceedings of the 2006 Winter Simulation Conference, eds. L. F. Perrone, F. P. Wieland, J. Liu, B. G. Lawson, D. M. Nicol, and R. M. Fujimoto, 529-535.

Y. Park and S.B. Ahn. Optimal assignment for check-in counters based on passenger arrival behaviour at an airport. Transportation Planning and Technology, 26(5):397-416, 2003. 
Zografos, K.G., and Madas, M.A. (2004b), "Design and Development of an Integrated Computational Platform for Total Airport Performance Analysis", Proceedings of the 2 International Congress on Transportation Research in Greece, Session on Air Transport, Athens, Greece, 26-27 February, 2004.

Zografos, K.G., Madas, M.A., van Eenige, M.J.A., Valdes, R.A., 2005. Integrated airport performance analysis through the use of the OPAL platform. Air Traffic Control Quarterly (ATCQ) 13 (4), 357-386.

\section{KEY TERMS AND DEFINITIONS}

Airport Planning \& Capacity: Airport planning encompasses capacity, master and regional planning, aviation forecasting, and airspace planning. Activities include providing planning guidance, producing the biennial National Plan of Integrated Airport Systems, developing capacity studies, collecting boarding and cargo data to determine airport categories.

Capacity: The airport operating level, expressed as the number of aircraft movements that can occur at an airport over a specified time period.

Commercial Aviation: Aircraft activity licensed by state or federal authority to transport passengers and/or cargo on a scheduled or non-scheduled basis.

Discrete Event Simulation: The process of codifying the behavior of a complex system as an ordered sequence of well-defined events. In this context, an event comprises a specific change in the system's state at a specific point in time.

Facility Design: Ensure a smooth flow of resources such as work, material, or information through a specific space within the system.

Terminal Building: That building on an airport which is used in making the transition between surface and air transportation.

Peak Hour: Represents that highest number of operations or passengers during the busiest hour of an average day of a peak month. 